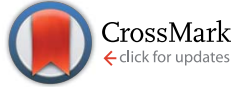

Cite this: RSC Adv., 2016, 6, 6209

Received 29th October 2015 Accepted 20th December 2015

DOI: $10.1039 / c 5 r a 22736 d$

www.rsc.org/advances

\section{Synthesis and optical properties of covalently bound Nile Red in mesoporous silica hybrids - comparison of dye distribution of materials prepared by facile grafting and by co-condensation routes $\dagger$}

\author{
Markus Börgardts, ${ }^{a}$ Kathrin Verlinden, ${ }^{\mathrm{b}}$ Manuel Neidhardt, ${ }^{\mathrm{c}}$ Tobias Wöhrle, ${ }^{\mathrm{c}}$ \\ Annika Herbst, ${ }^{\mathrm{b}}$ Sabine Laschat, ${ }^{\mathrm{c}}$ Christoph Janiak $^{\mathrm{b}}$ and Thomas J. J. Müller ${ }^{\star a}$
}

\begin{abstract}
The fluorescence dye Nile Red (NR) can be covalently ligated to hexagonally ordered, mesoporous silica materials (MCM-41) via co-condensation and post grafting routes in order to investigate possible differences in the dye distributions. The obtained hybrid materials display emission properties similar to free NR but in contrast to free dye molecules even aqueous gels are luminescent, rendering these materials particularly interesting for biolabeling applications. All materials were structurally characterized by nitrogen sorption measurements, small angle X-ray scattering (SAXS), and transmission electron microscopy (TEM). Their optical properties were characterized by UV/Vis and fluorescence spectroscopy.
\end{abstract}

\section{Introduction}

After the discovery of pure inorganic mesoporous silica materials in 1992, research on mesoporous composite materials modified by organic molecules quickly evolved. ${ }^{1-3}$ By chemical and physical manipulation of their pore systems, the properties of rigid silica and various functional molecules can be combined and lead to unique features of the hybrid materials in comparison to the individual components. As a consequence these novel composite materials open novel applications in various topical fields of research, such as catalysis, ${ }^{4}$ optical sensing, ${ }^{5,6}$ solid state lasers, ${ }^{7}$ and drug delivery..$^{8-10}$ For sensing applications mesoporous silica hybrids are particularly advantageous due to their pore structure (e.g. MCM-41) enabling facile mass transport at high rates, which is essential for quick response times to environmental changes. Furthermore, the shape and size of silica particles can be controlled by varying the

\footnotetext{
${ }^{a}$ Institut für Organische Chemie und Makromolekulare Chemie, Heinrich-Heine-Universität Düsseldorf, Universitätsstraße 1, D-40225 Düsseldorf, Germany. E-mail: ThomasJJ.Mueller@uniduesseldorf.de

${ }^{b}$ Institut für Anorganische Chemie und Strukturchemie, Heinrich-Heine-Universität Düsseldorf, Universitätsstraße 1, D-40225 Düsseldorf, Germany

'Institut für Organische Chemie, Universität Stuttgart, Pfaffenwaldring 55, D-70569 Stuttgart, Germany

$\dagger$ Electronic supplementary information (ESI) available: Structural characterization of hybrid materials $\mathbf{6}$, and 7 (nitrogen sorption, SAXS, and TEM), spectroscopic characterization of precursor $\mathbf{5}$ and hybrid materials $\mathbf{6}$ and 7 (UV/Vis and fluorescence), red-edge excitation shift of hybrid materials $\mathbf{6 b}$ and $7 e$, fluorescence quenching of hybrid materials $\mathbf{6 b}$ and $7 \mathbf{b}$. See DOI: 10.1039/c5ra22736d
}

synthetic conditions, thus rendering them also favorable for medicinal applications, such as drug delivery or biolabeling. ${ }^{11}$ Special sensitivity can be additionally introduced by modification of the silica surface with biochemical functionalities, such as antibodies. ${ }^{9}$

The simplest route of doping organic dyes into sol-gel matrices is the adsorption and entrapping of the chromophores during their synthesis. However, plain adsorption inevitably causes leakage and migration of the dyes, although this problem can be circumvented by covalent ligation of the dye to free silanol groups in the silica framework. In this manner, a dye containing a reactive functionality can be grafted onto the silanol groups of the silica matrix in the sense of a postsynthetic functionalization. Alternatively and quite elegantly in a highly convergent fashion, a dye with pending trialkoxysilyl functionality can be covalently anchored in the mesoporous structure in statu nascendi (co-condensation). ${ }^{12}$ Yet, the determination of the homogeneity of the dye distribution, especially at low dye loading proved to be difficult and only little research has been dedicated to the comparison of dye distribution of hybrid materials synthesized by post grafting methods and one-pot synthesis. Especially there is barely any comparison between the two most feasible synthesis methods of hybrid materials with similar structural properties, i.e. grafting onto commercially available mesoporous silica and co-condensation. ${ }^{13-15}$

Taking advantage of the inherent chemical, thermal and dimensional stability of silica hybrid materials various fluorescent dyes have already been incorporated into mesoporous silica by adsorption or covalent ligation, thus enhancing the photostability of the organic components. ${ }^{16,17}$ Most 
advantageously a co-condensation strategy could give rise to a homogenous distribution, thereby avoiding aggregationinduced self-quenching of the dye molecules. ${ }^{18,19}$

A typical fluorescence dye displaying emission selfquenching in the solid state is Nile Red (NR). NR possesses high fluorescence quantum yields in lipids and unpolar solvents and is widely used in biological applications as a lipophilic stain or a laser dye. ${ }^{\mathbf{2 0 - 2 2}}$ Moreover, the pronounced emission solvatochromicity allows its use as polarity sensor in cellular environments. ${ }^{23,24}$ Unfortunately, NR's water insolubility restricts its application to lipids and highly hydrophobic micro-environments. But still since NR's fluorescence does not interfere with the cellular autofluorescence (typically below 550 $\mathrm{nm}$ ), NR could be an ideal probe for biolabeling and thus recent work is dedicated to water-soluble, but still luminescent NR derivatives. ${ }^{25-27}$ As a consequence a new class of luminescent stains for intracellular imaging could evolve.

Upon incorporation of NR into mesoporous silica, aggregation-induced self-quenching in aqueous media should be suppressed, leading to hybrid materials suitable for biotechnological applications. ${ }^{28,29}$ In addition, these hybrids could be ligated to biomolecules by decorative functionalization of the outer surface of silica particles. ${ }^{9}$

Finally, these NR-silica hybrids should be still luminescent in the solid sol state. Potential applications can be envisioned in solid state dye lasers where the luminescent properties of the dye are concatenated with the inherent stability of the silica host structure, concomitantly avoiding toxic solvents and ensuring easier handling with potentially adjustable shape, e.g. as fibres. ${ }^{7,30}$ Moreover, solid-state fluorescent NR hybrids could be employed in security technology as near-infrared solid state dyes. ${ }^{31}$

Here we report the synthesis of NR-functionalized hybrid silica by the two most feasible synthetic methods i.e. postsynthetic grafting of commercial available MCM-41 and in situ co-condensation. Materials prepared by both routes were studied with respect to homogeneity as well as the effect of applied synthesis route and dye loading of the hybrid. Furthermore, the structural and optical properties of these novel hybrid materials are thoroughly studied and discussed.

\section{Results and discussion}

\section{Synthesis}

For the covalent ligation of NR to the silica materials a side chain with a terminal triethoxysilyl group had to be introduced. Starting from 3-diethylaminophenol (1), via the formation of the nitroso derivative 2 , the 2 -hydroxy substituted NR derivative 3 was obtained according to a literature procedure (Scheme 1). ${ }^{32}$ By Williamson ether synthesis the phenol 3 was transformed into the propargyl ether 4 in $24 \%$ yield. Finally, by $\mathrm{CuAAC}(\mathrm{Cu}-$ catalyzed alkyne-azide cycloaddition) ${ }^{33}$ of alkyne 4 with (3-azidopropyl)triethoxysilane the required terminal triethoxysilyl group was introduced ${ }^{34}$ to give the triethoxysilyl functionalized NR precursor 5 in $45 \%$ yield.

The NR silica hybrid materials 6 were synthesized via postsynthetic functionalization of commercially available MCM-41 with the precursor molecule 5 (postsynthetic grafting) and NR silica hybrid materials 7 were prepared via in situ cocondensation upon simultaneous formation of the mesoporous structure (in situ synthesis). To exclude dye leakage from the hybrid materials, Soxhlet extraction was performed until no more dye could be detected in the supernatant.

During the postsynthetic grafting, the triethoxysilane terminus of precursor 5 reacts with the free silanol groups exposed on the surfaces in the pores. The major advantage of this strategy is retaining the initial pore structure of the silica material. However, the major drawback is the potential nonuniform distribution of the organic molecules and pore clogging at elevated substrate concentrations as a consequence of preferential functionalization at the pore openings.

In contrast, a homogenous distribution can be achieved by the in situ co-condensation approach where tetraethoxysilane (TEOS), the precursor dye molecule, and the templating agent are present in the same pot. Especially in cases where selfquenching of the emission of fluorophores can be expected at higher concentrations a homogeneous distribution and dilution is indispensable. Furthermore, it is still possible to obtain materials at higher degrees of loading since pore clogging is not an issue. However, since the dye molecules are immediate components of the silica material, an increase in organic functionalization might cause a decrease in mesoporous order, inevitably causing a total collapse of the structural order at high doping levels (Scheme 2).

\section{Structural characterization}

Nitrogen sorption isotherms. Analysis of the hybrid materials by $\mathrm{N}_{2}$ sorption gives isotherms which are of type IV in the IUPAC classification. These isotherms represent the particular situation of mesoporous materials possessing adsorption inside micropores at low relative pressures followed by multilayer adsorption and by capillary condensation in the pressure region $p / p_{0}$ between 0.25 and 0.40 (Fig. 1 and S1 and S2 in ESI $\dagger$ ). ${ }^{35}$ Pure MCM-41 exhibits a H4 hysteresis loop in the higher pressure region $\left(p / p_{0}=0.45\right.$ to 1$)$ which can be attributed to slit-shaped pores or internal voids of irregular shape. ${ }^{35-37}$ This behavior is also found for the co-condensed and grafted materials but with a less pronounced hysteresis loop. In addition, these materials show a $\mathrm{H} 1$ hysteresis loop in the region of the capillary condensation step which can be rationalized with a high degree of pore-size uniformity. ${ }^{38,39}$

A further distinction between the co-condensed (7) and grafted (6) materials can be made by means of their specific surface areas of $\sim 1000$ and $\sim 800 \mathrm{~m}^{2} \mathrm{~g}^{-1}$, respectively (Table 1 ). These differences can be rationalized by the modified synthesis conditions of the co-condensed material relative to the synthesis of pure MCM-41 material. Within the series of cocondensed materials, hybrids $7 \mathbf{f}-\mathbf{h}$ exhibit slightly lower surface areas and pore volumes than the other samples, as well as higher structural disorder, as can be seen in the hysteresis loop of the capillary condensation step. This could be due to a higher dye content inside the pores as this would cause a decrease in surface area. But it is more likely that this decrease 
<smiles>C#CCOc1ccc2c(=O)cc3oc4cc(N(CC)CC)ccc4nc-3c2c1</smiles>

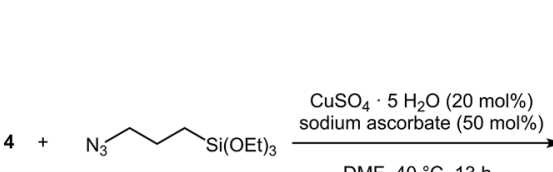

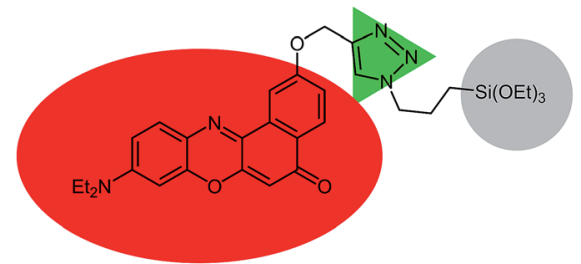

$5(45 \%)$

Scheme 1 Synthesis of the triethoxysilyl functionalized NR precursor 5 .

is dependent on the modified synthesis conditions as it is known that the structure of MCM materials can be controlled by the addition of alcohols. ${ }^{40-42}$ Thus, as in the synthesis of $\mathbf{7 f - h}$ a higher amount of methanol was applied due to solubility issues of the precursor molecule, it is very likely that this caused a decrease in the surface area rather than a higher dye content in the micromolar range. For the grafted hybrids $6 a-i$ the surface areas range between 748 and $878 \mathrm{~m}^{2} \mathrm{~g}^{-1}$, whereas neat MCM-41 has a surface area of $806 \mathrm{~m}^{2} \mathrm{~g}^{-1}$. As the experimental error in BET surface area determination can be $\pm 50 \mathrm{~m}^{2} \mathrm{~g}^{-1}$ the values overlap with their error margins. So functionalized materials 6a-i do not differ much from neat silica, indicating that dye doping with $0.6-23 \mu \mathrm{mol} \mathrm{g}^{-1}$ does not lead to a significant variation of the surface area and pore volume.

The pore size distributions of the hybrid materials were obtained by DFT calculations from the $\mathrm{N}_{2}$ isotherms (Fig. 2, S3 and S4 in ESI $\dagger$ ). These calculated distributions are bimodal and relatively narrow around diameters of $c a .1 .5$ and $2.8 \mathrm{~nm}$ for MCM-41 and its co-condensed and grafted hybrids. Noteworthy, the volume fraction of the smaller pores around $1.5 \mathrm{~nm}$ and of

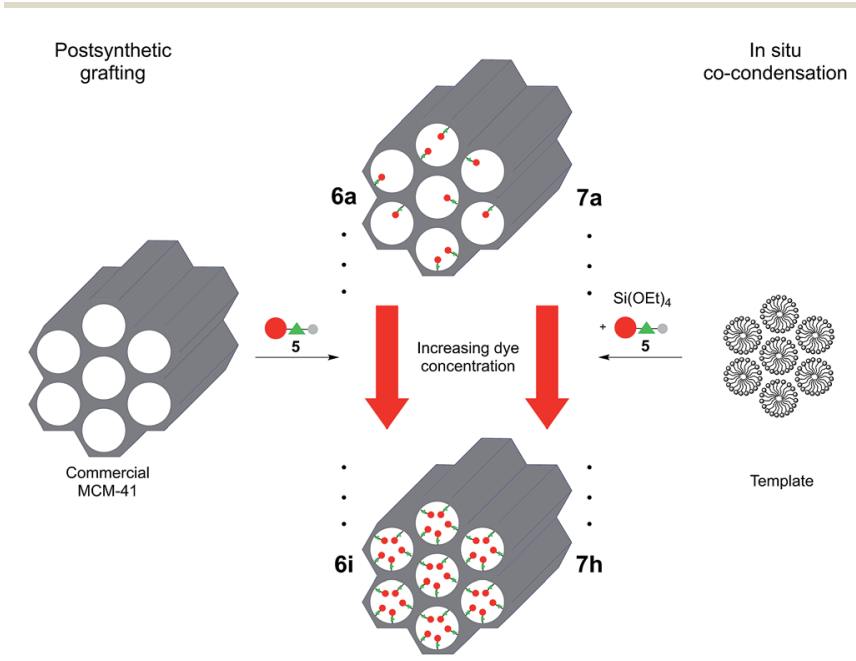

Scheme 2 Synthesis of grafted $(6 a-i)$ and co-condensed $(7 a-h)$ hybrid materials with different dye loadings. pores larger than $3 \mathrm{~nm}$ has decreased in 6 and especially 7 compared to neat MCM-41. As there is no decrease of the volume fraction for low and high loaded materials, this change is attributed to the dye extraction conditions leading to slightly modified pores.

These results imply that the surface area as well as the pore size distribution is an inherent feature of the employed silica material or rather its synthesis conditions. They are not affected by the loading with varying amounts of dye. The shape of the sorption isotherms and their capillary condensation steps show no distinct change or shift at higher loadings of dye as was the case for organic molecules at concentrations up to $0.77 \mathrm{mmol}$ $\mathrm{g}^{-1}$ incorporated in the MCM-41 type material. ${ }^{43}$

\section{Small angle X-ray scattering (SAXS)}

In order to gain deeper insight into the structure of the hybrid materials the samples were studied by small angle X-ray scattering (SAXS) (Table 2, Fig. 3). The post-grafted hybrid materials 6a-i exhibit 4 reflections corresponding to the (100), (110), (200) and (210) planes, whose $1 / d$ values match with a relation of

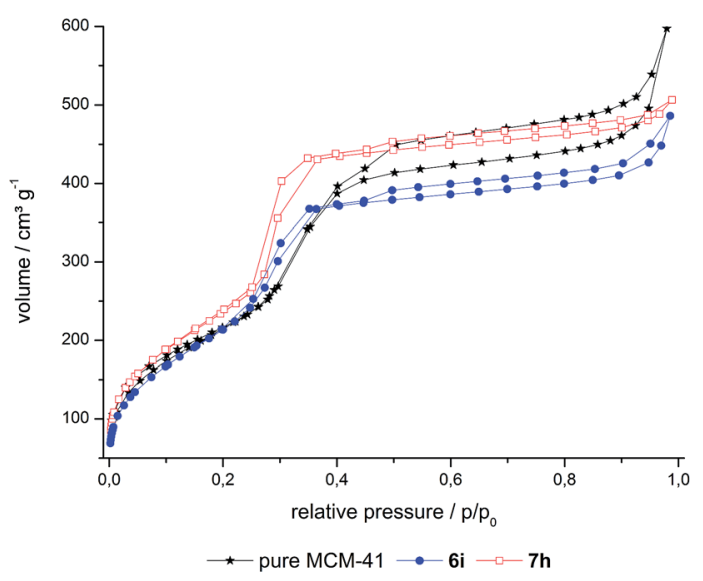

Fig. $1 \mathrm{~N}_{2}$-sorption isotherms of a grafted (6i), a co-condensed (7h) hybrid material and pure MCM-41. See Fig. S1 and S2 in ESI† for isotherms of $6 \mathrm{a}-\mathrm{h}$ and $7 \mathrm{a}-\mathrm{g}$. 


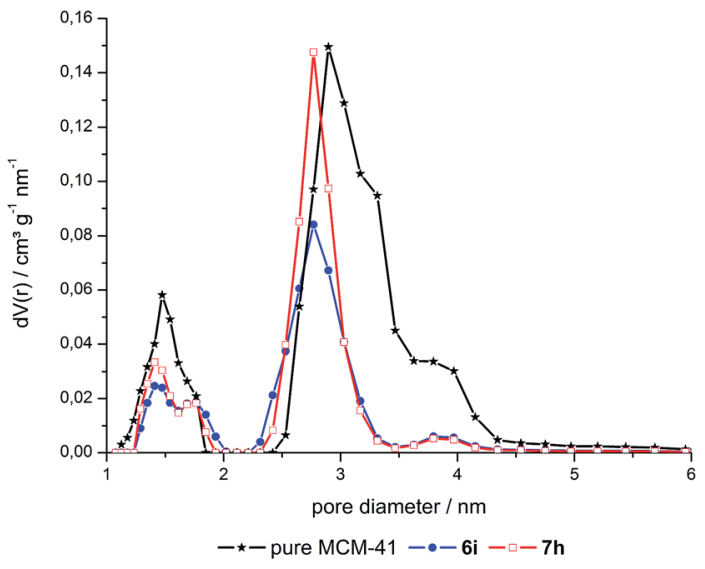

Fig. 2 Pore size distribution of a grafted hybrid (6i), a co-condensed hybrid (7h) and pure MCM-41.

$1: \sqrt{ } 3: \sqrt{ } 4: \sqrt{ } 7$ which is typical for two-dimensional ordered hexagonal mesostructured material possessing $16 \mathrm{~mm}$ symmetry. ${ }^{38,44}$ Thus, no change in the mesostructure can be observed in comparison to neat MCM-41. Furthermore, the post-grafted hybrids as well as the neat MCM- 41 exhibit lattice planes around $4.0 \mathrm{~nm}$ which is almost unchanged compared to the co-condensed hybrid materials. Like in the gas sorption analysis, the co-condensed materials $\mathbf{7 g}$-h $\mathbf{h}$ show slightly smaller lattice planes as a consequence of the adjusted synthesis conditions.

In a detailed investigation of the lattice parameters for the differently dye loaded materials, no significant deviation can be observed. All co-condensed materials possess $d_{100}$ spacing in a range from 3.88 to $4.03 \mathrm{~nm}$ corresponding to lattice parameters ranging from 4.47 to $4.65 \mathrm{~nm}$. In addition, no decrease of the reflection intensity is observed which also suggests that the hexagonal structure is not influenced by the addition of dye. In summary it can be concluded that the applied dye concentrations in a micromolar range do not interfere with the formation

Table 1 Pore volume and surface area of pure MCM-41, grafted (6) and co-condensed (7) hybrids

\begin{tabular}{|c|c|c|c|c|c|}
\hline \multicolumn{3}{|l|}{ Grafted } & \multicolumn{3}{|c|}{ Co-condensed } \\
\hline Sample & $\begin{array}{l}\text { Pore volume } \\
{\left[\mathrm{cm}^{3} \mathrm{~g}^{-1}\right]}\end{array}$ & $\begin{array}{l}\text { BET surface } \\
\text { area } \\
{\left[\mathrm{m}^{2} \mathrm{~g}^{-1}\right]}\end{array}$ & Sample & $\begin{array}{l}\text { Pore } \\
\text { volume } \\
{\left[\mathrm{cm}^{3} \mathrm{~g}^{-1}\right]}\end{array}$ & $\begin{array}{l}\text { BET surface } \\
\text { area } \\
{\left[\mathrm{m}^{2} \mathrm{~g}^{-1}\right]}\end{array}$ \\
\hline $\begin{array}{l}\text { Neat } \\
\text { MCM-41 }\end{array}$ & 0.77 & 806 & & & \\
\hline $6 a$ & 0.66 & 808 & $7 a$ & 0.93 & 1042 \\
\hline $6 b$ & 0.69 & 868 & $7 \mathbf{b}$ & 0.95 & 1060 \\
\hline $6 c$ & 0.65 & 748 & $7 c$ & 0.93 & 1044 \\
\hline 6d & 0.71 & 878 & $7 d$ & 0.94 & 1061 \\
\hline $6 e$ & 0.64 & 781 & $7 e$ & 0.97 & 1075 \\
\hline $6 f$ & 0.63 & 750 & $7 f$ & 0.81 & 995 \\
\hline $6 \mathrm{~g}$ & 0.69 & 851 & $7 \mathrm{~g}$ & 0.77 & 995 \\
\hline $6 \mathrm{~h}$ & 0.66 & 821 & $7 \mathrm{~h}$ & 0.74 & 944 \\
\hline $6 i$ & 0.66 & 852 & & & \\
\hline
\end{tabular}

of the mesoporous structure as long as the synthesis conditions remain constant.

\section{Transmission electron microscopy (TEM)}

In contrast to the gas sorption and SAXS analysis of the hybrid materials where a hexagonal ordering of the silica is deduced from the experimental data, the characterization by transmission electron microscopy (TEM) gives unambiguous evidence for the structural ordering as a direct image of the sample. As shown in Fig. 4, the hexagonal, honeycomb-like ordering of the pores as well as the two-dimensional organization of channels is evident when the sample is viewed in direction of the pores and perpendicular to the pore channels, respectively. The quality of the obtained silica structures are comparable to commercial MCM-41 and show no dependence on the amount of incorporated dye. The assumption of voids inside the hybrid material, as indicated by the hysteresis in the sorption isotherms, can be confirmed in the TEM images. Thus all structural analysis are mutually consistent with each other and confirm the assumed hexagonal mesoporous ordering as well as the absence of an influence of the dye incorporation (in the micromolar range) on the structural ordering.

\section{Excitation and emission properties}

Determination of dye incorporation. As a consequence of low amounts of dye employed in the hybrid synthesis to avoid self-quenching of fluorescence, only UV/Vis spectroscopy proved useful for the determination of the effective dye concentration. Therefore, suspensions of the hybrid materials in DMSO were analyzed. But as the loading of dye in the hybrid materials had to be calculated from the UV/Vis spectra via the Lambert-Beer's law, the molar extinction coefficient for the silica matrix-embedded dye had to be determined. However, this cannot be done precisely as there is no reference substance and thus the molar extinction coefficient had to be estimated. For a reasonable estimation the environment of the dye inside the hybrid material was modelled and the molar extinction coefficient of the precursor molecule was determined. Although it cannot completely be ruled out that these calculations are error-prone due to the estimation of the molar extinction coefficient, the determination of $\varepsilon$ in DMSO should give reasonable estimate as the absorption spectrum of the free precursor molecule is essentially identical to the absorption spectra of the hybrid materials suspended in DMSO. This suggests that the environment of the silica matrix-embedded dye is comparable to pure DMSO. Otherwise the absorption would be significantly shifted caused by changes of the environment polarity. The regression analysis of determined concentrations $v s$. applied concentrations served for gaining higher accuracy by recalculating the concentrations (Fig. 5, Table 3).

The incorporation of dye into the silica material proceeds more effectively by grafting than by co-condensation. The slopes of the regression lines indicate an incorporation of approximately half of the applied dye concentration in the hybrid material obtained by grafting, whereas for the co-condensed material only one third of the applied concentration is incorporated. 
Table 2 Lattice parameters and lattice planes of grafted (6) and co-condensed (7) hybrid materials

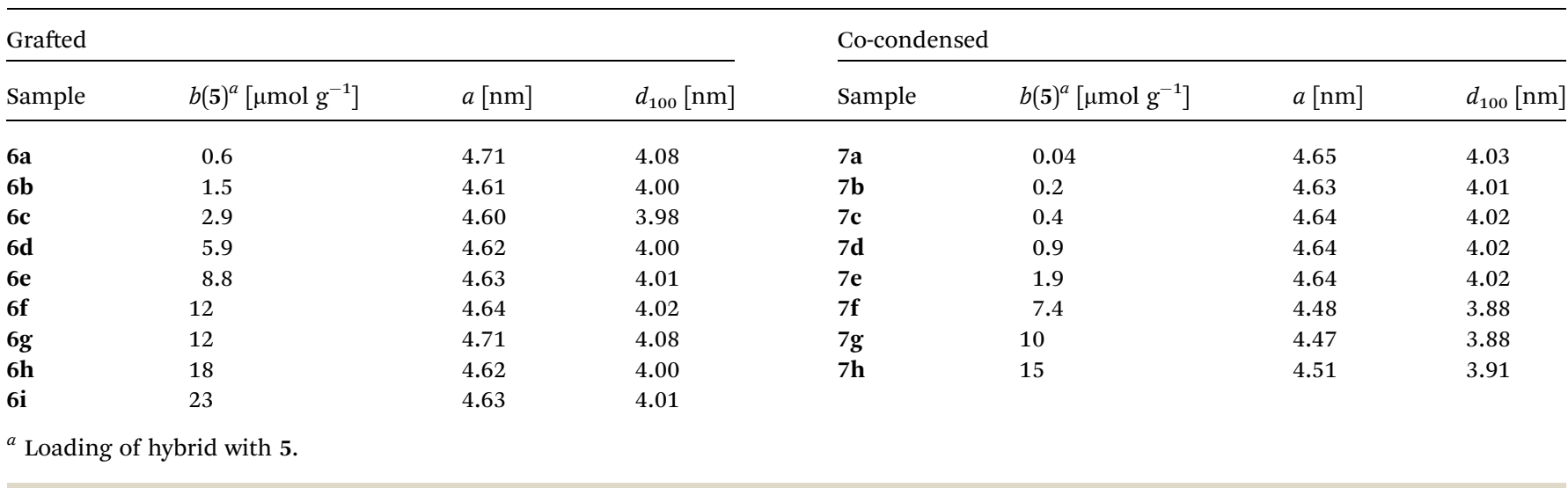

Although a lower concentration of reactive silanol groups can be expected due to calcination of the commercial MCM-41 source a higher degree of incorporation of dye by grafting was proven.

As a consequence the lower applied dye concentration is still sufficient for the grafted materials, in comparison with the equivalent loaded co-condensed hybrids.

\section{Fluorescence quantum yields}

The total fluorescence of nine grafted (6) and eight cocondensed (7) hybrid materials in the solid state was determined using an integrating sphere (Ulbricht setup). The quantum yields in dependence on the matrix-embedded dye concentration are shown in Fig. 6 and Table 4. Both types of materials, co-condensed as well as grafted, reveal a similar dependence of the quantum yield on the concentration.

These materials display fluorescence even at very low dye doping levels, such as in the nanomolar range. With increasing dye concentration a steep increase in quantum yield is detected up to a maximum concentration around $2 \mu \mathrm{mol} \mathrm{g}{ }^{-1}$. Quantum yields of 18 and $23 \%$ for the co-condensed and grafted material, respectively, were determined. At higher dye loading the quantum yields decrease even below the quantum yields for the

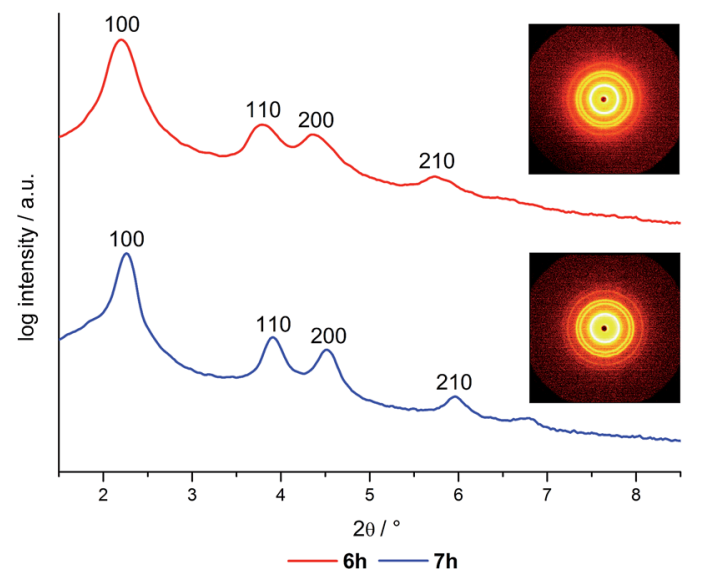

Fig. 3 SAXS pattern of $6 \mathrm{~h}$ and $7 \mathrm{~h}$. nanomolar dye doping levels. This asymptotic convergence to a completely quenched fluorescence very likely arises from the fluorescence quenching of NR at higher concentrations, as reported for free NR in the solid state.

Although a similar dependence of the quantum yield on the dye loading can be observed, the maximum quantum yield of the co-condensed material 7 is about $4 \%$ less than for the grafted material 6. Moreover, the grafted hybrids reach a quantum yield of $7 \%$ even at high concentrations, whereas the co-condensed materials are nearly quenched (2\%). A possible explanation for this behavior could be the weak acidity of the silanol groups $\left(\mathrm{p} K_{\mathrm{a}} \approx 7.1\right),{ }^{45}$ which can protonate the NR molecules, and thereby cause fluorescence quenching.

If the functionalization of the co-condensed hybrids 7 can be assumed to take place preferentially inside the pores, the

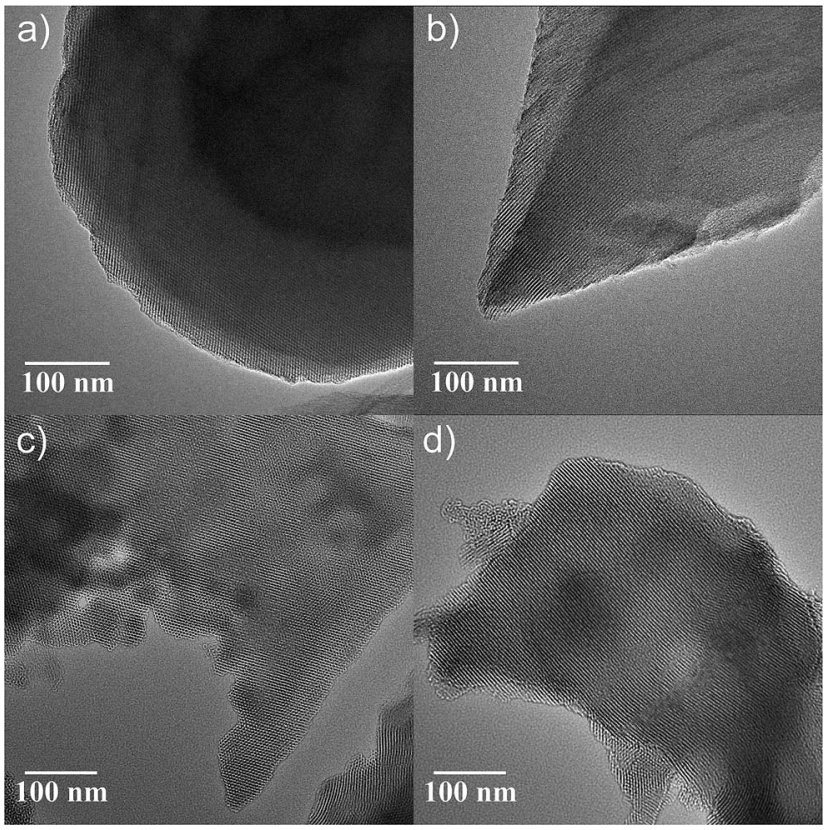

Fig. 4 (a) TEM image of 7h along the channel direction and (b) TEM image of $7 \mathrm{~h}$ perpendicular to the channel direction as well as (c) TEM image of $6 i$ along the channel direction and (d) TEM image of $6 i$ perpendicular to the channel direction. 


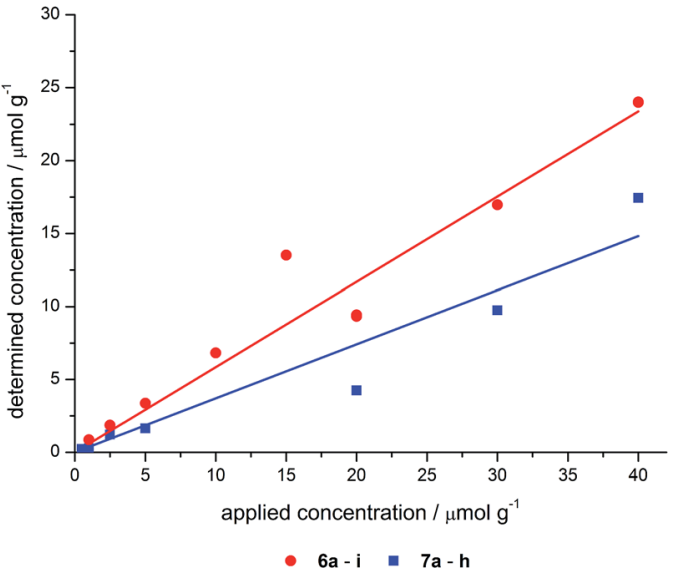

Fig. 5 Applied vs. determined concentrations of the hybrid materials 6 and 7 (linear regression analysis gives for grafted: $y=0.585 x, R^{2}=$ 0.969; and co-condensed: $y=0.371 x, R^{2}=0.948$ ).

fluorophore molecules will face an environment with a higher effective concentration of silanol groups in comparison to predominantly outside bound dyes as expected for the grafted case 6 . Thus, the dye molecules in co-condensed hybrids 7 will experience a higher degree of protonation and quenching of the NR luminophore compared to the grafted hybrids $6 .^{46}$

\section{Solvatochromism}

The solvatochromic properties of the 2-hydroxy-substituted NR derivative 3 are not significantly affected by functionalization to give the precursor molecule 5 . The excitation as well as emission maxima remain almost unchanged, except for the measurement in diethyl ether where the maxima of the precursor molecule $\mathbf{5}$ are slightly hypsochromically shifted relative to the 2-hydroxy substituted NR 3 (Fig. 7).

Upon incorporation of the NR derivative 5 into mesoporous silica materials (as studied for hybrid material 7e) the solvatochromic behavior is mostly retained (Fig. 8). However, it was found that the hybrid materials show a red-edge excitation

Table 3 Applied and calculated concentrations of the grafted (6) and co-condensed (7) hybrid materials

\begin{tabular}{|c|c|c|c|c|c|}
\hline \multicolumn{3}{|c|}{ Grafted } & \multicolumn{3}{|c|}{ Co-condensed } \\
\hline & $\begin{array}{l}\text { Applied } \\
\text { conc. of } \mathbf{5} \\
{\left[\mu \mathrm{mol} \mathrm{g}{ }^{-1}\right]}\end{array}$ & $\begin{array}{l}\text { Calculated } \\
\text { conc. of } \mathbf{5} \\
{\left[\mu \mathrm{mol} \mathrm{g}{ }^{-1}\right]}\end{array}$ & & $\begin{array}{l}\text { Applied } \\
\text { conc. of } \mathbf{5} \\
{\left[\mu \mathrm{mol} \mathrm{g}{ }^{-1}\right]}\end{array}$ & $\begin{array}{l}\text { Calculated } \\
\text { conc. of } 5 \\
{\left[\mu \mathrm{mol} \mathrm{g}{ }^{-1}\right]}\end{array}$ \\
\hline $6 a$ & 1.0 & 0.6 & $7 \mathbf{a}$ & 0.1 & 0.04 \\
\hline $6 b$ & 2.5 & 1.5 & $7 \mathbf{b}$ & 0.5 & 0.2 \\
\hline $6 c$ & 5.0 & 2.9 & $7 c$ & 1.0 & 0.4 \\
\hline 6d & 10 & 5.9 & $7 d$ & 2.5 & 0.9 \\
\hline $6 e$ & 15 & 8.8 & $7 e$ & 5.0 & 1.9 \\
\hline $6 f$ & 20 & 12 & $7 f$ & 20 & 7.4 \\
\hline $6 \mathrm{~g}$ & 20 & 12 & $7 \mathrm{~g}$ & 30 & 11 \\
\hline $6 h$ & 30 & 18 & $7 \mathbf{h}$ & 40 & 15 \\
\hline $6 \mathbf{i}$ & 40 & 23 & & & \\
\hline
\end{tabular}

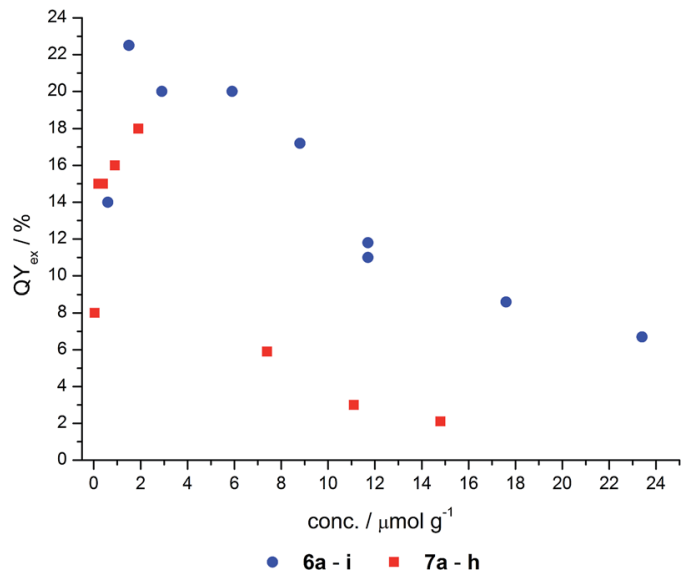

Fig. 6 Quantum yields of grafted (6) and co-condensed (7) hybrids.

shift (REES) known from polar dyes in viscous solvents. ${ }^{47-50}$ Thus, since it was not possible to obtain absorption spectra in the solid state and, except for DMSO, in suspension, excitation spectra were recorded for the determination of the absorption maxima. But due to the previous discussion it was not possible to correct these excitation spectra for the inner filter effect. It cannot be ruled out that the measured spectroscopic data are slightly error-prone. However, these systematic errors become negligible as emission spectra were always recorded at excitation in the short wavelength part of the excitation spectra where no shift of the emission spectra could be observed (vide infra Fig. 16).

Upon changing the environment of the dye the spectroscopic properties are also influenced. The excitation as well as emission maxima of hybrid material 7e are bathochromically shifted in comparison to precursor 5 (Fig. 9 and 10).

Most strikingly, both spectra reveal a much smaller range of emission and excitation maxima for the hybrid material than for the precursor molecule 5. Whereas the emission of precursor 5 shifts by $4000 \mathrm{~cm}^{-1}$ from hexane to water, the shift decreases to about $2000 \mathrm{~cm}^{-1}$ for the hybrid material 7e. This can be explained by the dominance of the siloxy environment in

Table 4 Quantum yields of the grafted (6) and co-condensed (7) hybrid materials

\begin{tabular}{|c|c|c|c|c|c|}
\hline \multicolumn{3}{|c|}{ Grafted } & \multicolumn{3}{|c|}{ Co-condensed } \\
\hline & $\begin{array}{l}\text { Calculated conc. } \\
\text { of } 5\left[\mu \mathrm{mol} \mathrm{g}^{-1}\right]\end{array}$ & $\begin{array}{l}\text { Quantum } \\
\text { yield }\end{array}$ & & $\begin{array}{l}\text { Calculated conc. } \\
\text { of } 5\left[\mu \mathrm{mol} \mathrm{g}{ }^{-1}\right]\end{array}$ & $\begin{array}{l}\text { Quantum } \\
\text { yield }\end{array}$ \\
\hline $6 a$ & 0.6 & 14 & $7 \mathbf{a}$ & 0.04 & 8.0 \\
\hline $6 b$ & 1.5 & 23 & $7 \mathbf{b}$ & 0.2 & 15 \\
\hline $6 c$ & 2.9 & 20 & $7 c$ & 0.4 & 15 \\
\hline $6 d$ & 5.9 & 20 & $7 d$ & 0.9 & 16 \\
\hline $6 e$ & 8.8 & 17 & $7 e$ & 1.9 & 18 \\
\hline $6 f$ & 12 & 12 & $7 f$ & 7.4 & 5.9 \\
\hline $6 g$ & 12 & 11 & $7 g$ & 11 & 3.0 \\
\hline $6 h$ & 18 & 8.6 & $7 \mathbf{h}$ & 15 & 2.1 \\
\hline $6 i$ & 23 & 6.7 & & & \\
\hline
\end{tabular}




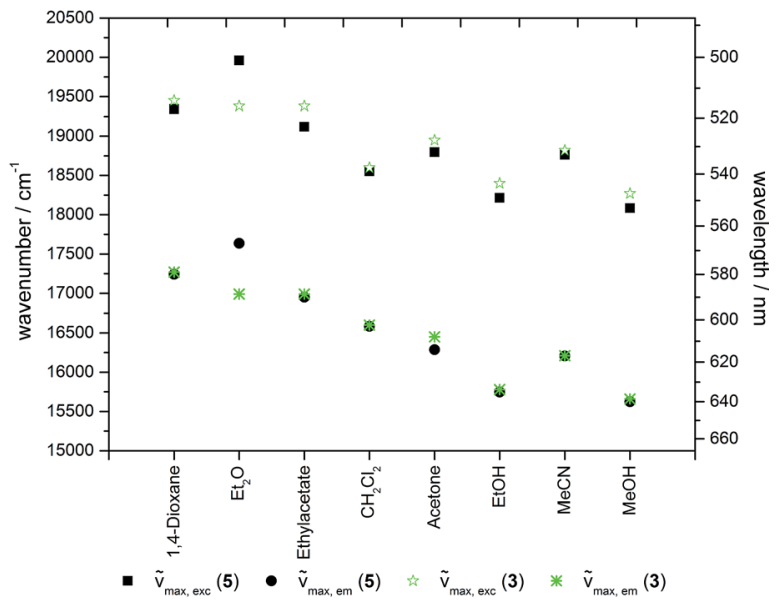

Fig. 7 Excitation and emission maxima of 2-hydroxy substituted NR (3) and precursor molecule 5 .

the pores, which is only affected to a minor extend upon changing the solvent polarity in the pores. This assumption is additionally supported by the emission maxima of the hybrid material in the solid state as indicated by the grey line at $643 \mathrm{~nm}$ in Fig. 9. Only the emission of hybrid material 7e suspended in ether or ester causes a hypsochromic shift of the emission maximum and the suspension in water leads to a significant bathochromic shift relative to the emission of $7 \mathbf{e}$ in solid state. The redshift for the hybrid material in water relative to the emission in the solid state can be rationalized by extensive hydrogen bonding, leading to a better stabilization of the excited state. The reverse is true for hydrogen-bond accepting solvents, such as ethers and esters which induce a blue shift of the emission.

The effect of the solvent polarity on the excitation spectra is not strongly pronounced, possibly due to the lower sensitivity of the electronic ground state to polarity changes. However, slight deviations due to an inner filter effect have to be taken into account.

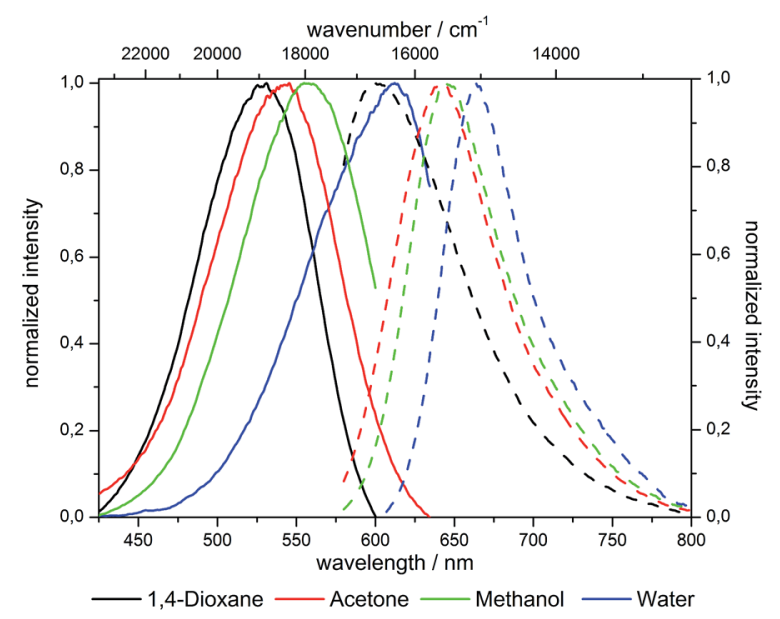

Fig. 8 Solvatochromism of 7e.

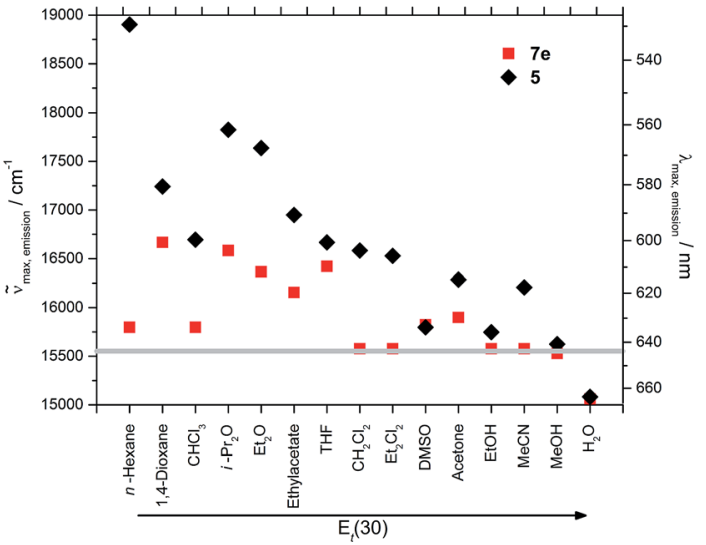

Fig. 9 Emission maxima of 5 and $7 e$ in different solvents (grey line at $643 \mathrm{~nm}$ represents the emission of the hybrid material in the solid state).

Furthermore, the excitation as well as emission spectra of precursor 5 and hybrid material $7 \mathrm{e}$ do not change for measurements in methanol, DMSO and water. In all three cases the environment created by the silica matrix is comparable to the environment of the dye in the respective solvent. This is also reflected in the differences in the Stokes shifts of the precursor molecule 5 and the hybrid material 7e (Fig. 11).

Some solvents hardly show any change in the Stokes shift of the hybrid material 7e compared to precursor molecule 5, although their excitation and emission maxima vary significantly. A striking example is the identical Stokes shift of precursor $5\left(\tilde{v}=1600 \mathrm{~cm}^{-1}\right)$ and hybrid material $7 \mathrm{e}(\tilde{\nu}=1600$ $\mathrm{cm}^{-1}$ ) in hexane, although the emission and excitation of hybrid $7 \mathrm{e}$ is shifted bathochromically by $3100 \mathrm{~cm}^{-1}$ in comparison to compound 5 (Fig. 9 and 10). Thus, it can be concluded that the incorporation of the dye into a silica matrix significantly changes the spectroscopic properties but the influence of the solvent polarity on these properties is comparable for both the free precursor 5 and the hybrid material 7 e.

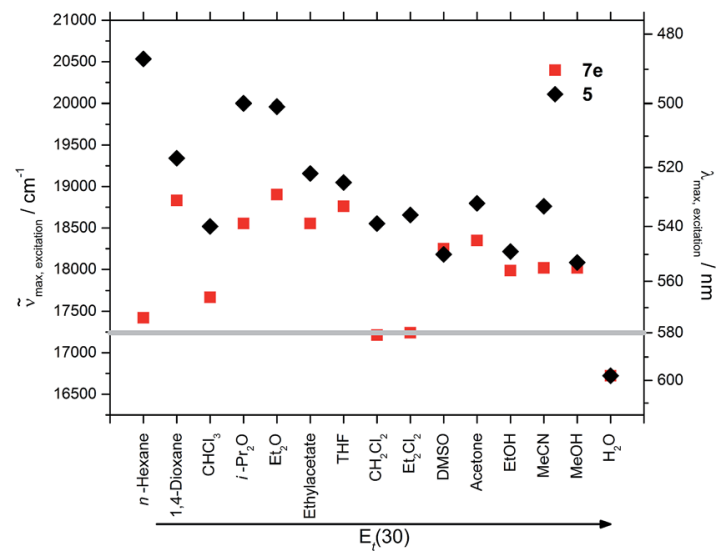

Fig. 10 Excitation maxima of 5 and $7 e$ in various solvents (grey line at $580 \mathrm{~nm}$ represents the excitation of the hybrid material in the solid state). 


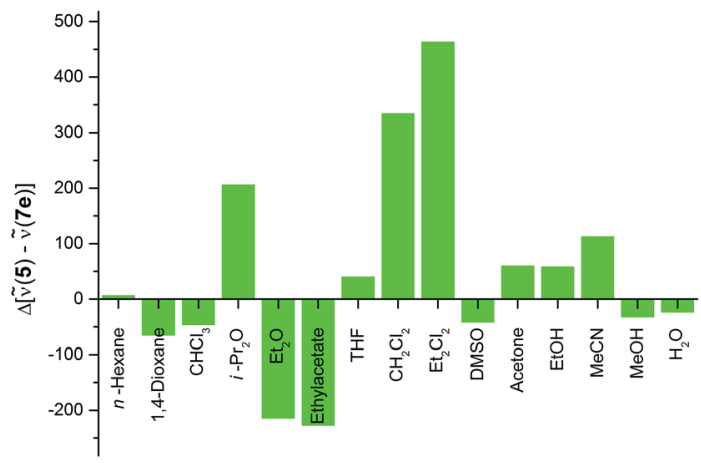

Fig. 11 Difference between Stokes shifts of precursor molecule 5 and hybrid material 7e.

Comparing the excitation spectra of the differently loaded hybrid materials the effect of loading levels on the excitation maxima for the grafted (6) and co-condensed (7) hybrids can be considered to be only minimal. For instance the excitation maximum of grafted material $\mathbf{6 a}$ at $589 \mathrm{~nm}$ is shifted bathochromically for material $\mathbf{6 c}$ by approximately $100 \mathrm{~cm}^{-1}$ accompanied by a decrease in intensity. The co-condensed hybrids 7 show a similar trend by redshifting from 572 (7c) to $579 \mathrm{~nm}$ (7e) (Fig. 12) by approximately $200 \mathrm{~cm}^{-1}$ concomitantly showing a decrease in excitation intensity with increasing concentration. In addition, the shape of the excitation spectra is altered as at the red-edge a relative sharp signal arises whereas the intensity at $590 \mathrm{~nm}$ (grafted hybrids 6) and $580 \mathrm{~nm}$ (cocondensed hybrids 7) decreases even further. This effect is attributed to the primary inner filter effect leading to an attenuation of the excitation light and resulting in a virtual redshift at high dye concentrations.

The emission spectra indicate a pronounced red shift by $1000 \mathrm{~cm}^{-1}$ upon increase of the dye concentration from $10^{-7}$ over $10^{-6}$ to $10^{-5} \mathrm{~mol} \mathrm{~g}^{-1}$ (Fig. 13). This bathochromic shift is identical for grafted (6) and co-condensed (7) materials as

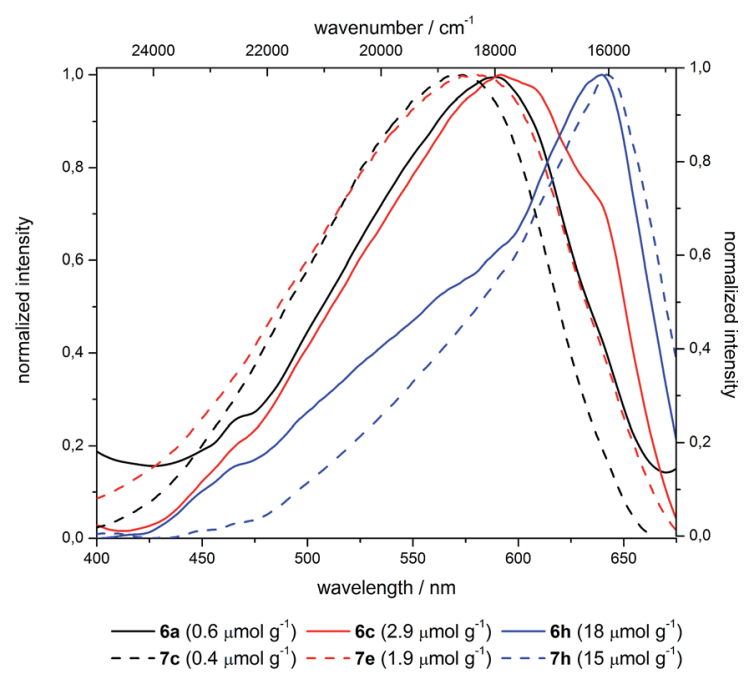

Fig. 12 Excitation spectra of selected grafted (6) and co-condensed (7) hybrid materials with variable dye loading $\left(\lambda_{\text {emission }}=700 \mathrm{~nm}\right)$. indicated by almost superimposable spectra at comparable dye loading.

Thus, this bathochromic shift can be attributed to reabsorption of the hypsochromic part of the emission at higher concentrations by dyes with small Stokes shifts. ${ }^{47}$ Although NR in general exhibits a large Stokes shift after incorporation in silica such reabsorption events become possible (Fig. 14)..$^{51}$

There is no evidence for the formation of aggregates although the excitation spectra display a different shape and a slight red shift at higher dye concentrations. These findings could imply the forming of aggregates, but considering the spectroscopic data from reports on NR aggregation this scenario seems unlikely in our case. ${ }^{28,51-54}$ If the alteration of shape in the excitation spectra was caused by aggregation, it would be quite unlikely that for the grafted and co-condensed materials, despite their very different synthesis conditions, nearly identical aggregates would be formed. Furthermore, literature reported aggregates of NR adsorbed in MCM-41 materials and suspended in dichloromethane possess full width at half maximum (fwhm) values of their emission band around $1000 \mathrm{~cm}^{-1} \cdot{ }^{54}$ Even though these values are quite high, they become possible due to higher disorder in a restricted environment leading to a broadening of the emission band. ${ }^{55,56}$ But comparing the fwhm values of the synthesized materials which are around $1500 \mathrm{~cm}^{-1}$ for hybrids suspended in dichloromethane and even $2000 \mathrm{~cm}^{-1}$ in solid state, aggregation seems even more unlikely. In addition there is no reduction of fwhm at high dye loading levels, relative to the low loaded hybrid material.

Moreover, there is no change in the absorption spectra of the suspensions of hybrid materials in DMSO, except for a shoulder at $640 \mathrm{~nm}$ (Fig. S25 and S26, ESI $\dagger$ ) for some hybrid materials which can be attributed to protonated NR species. This is additionally supported by fluorescence quenching studies. Therefore, reabsorption effects in the solid state causing

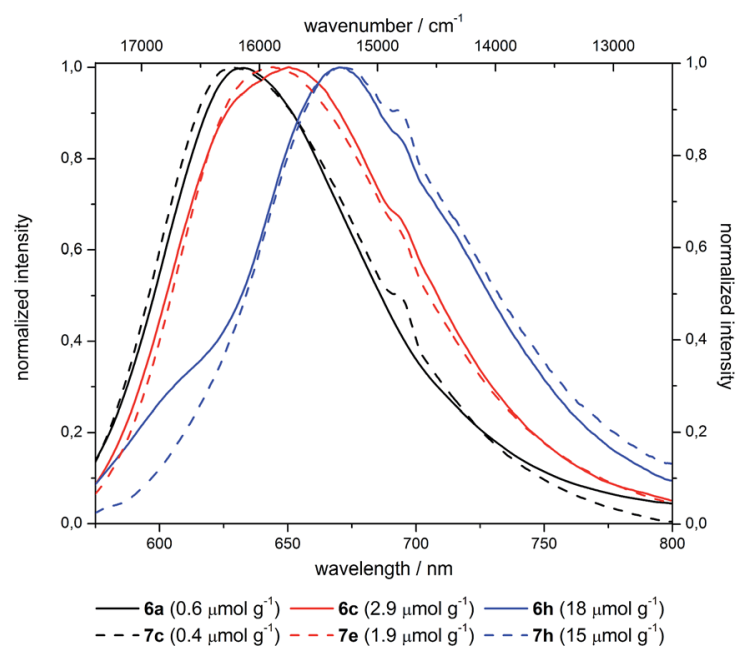

Fig. 13 Emission spectra of selected differently loaded grafted (6) and co-condensed (7) hybrid materials (shoulder at $695 \mathrm{~nm}$ is a measurement caused artefact). 


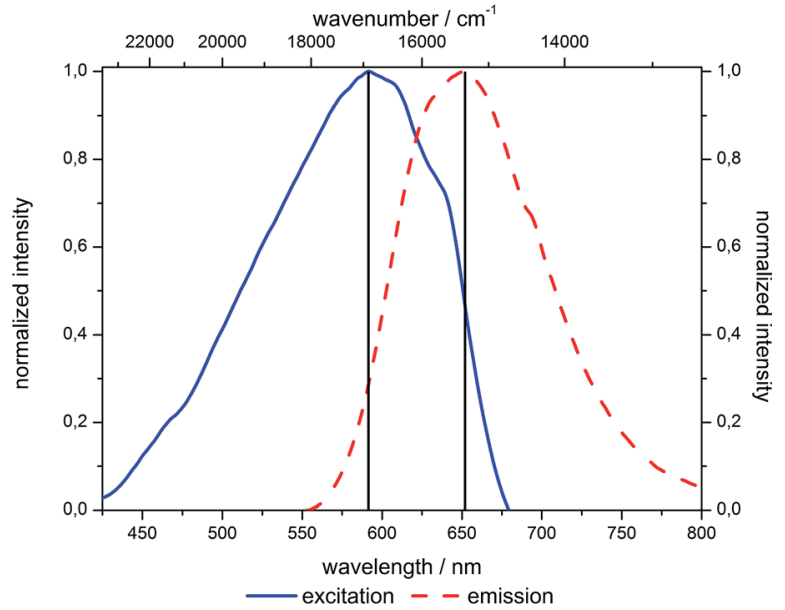

Fig. 14 Excitation and emission spectra of $6 c$ (in the solid state).

a bathochromic shift are by far more plausible than aggregate formation. ${ }^{46,57}$

The effect of REES can be found for the hybrid materials suspended in different solvents as well as in the solid state, although less pronounced. For hybrid materials $6 \mathbf{f}$ and $7 \mathrm{~g}$ the emission shifts bathochromically by 133 and $88 \mathrm{~cm}^{-1}$, respectively, upon excitation at 546 and $664 \mathrm{~nm}$. This effect is much more pronounced for the hybrid materials in suspension as shown in Fig. 15, with maximum shifts of about $1000 \mathrm{~cm}^{-1}$. It is striking that predominantly the grafted material shows bigger shifts compared to the co-condensed hybrids and that nearly no REES can be observed in water.

A thorough inspection of the REES of the grafted (6b) and co-condensed (7e) hybrid materials suspended in acetone clearly shows that at excitation wavelengths lower than $540 \mathrm{~nm}$ both materials do not distinctly shift the emission in dependence of the excitation wavelength (Fig. 16). Only upon

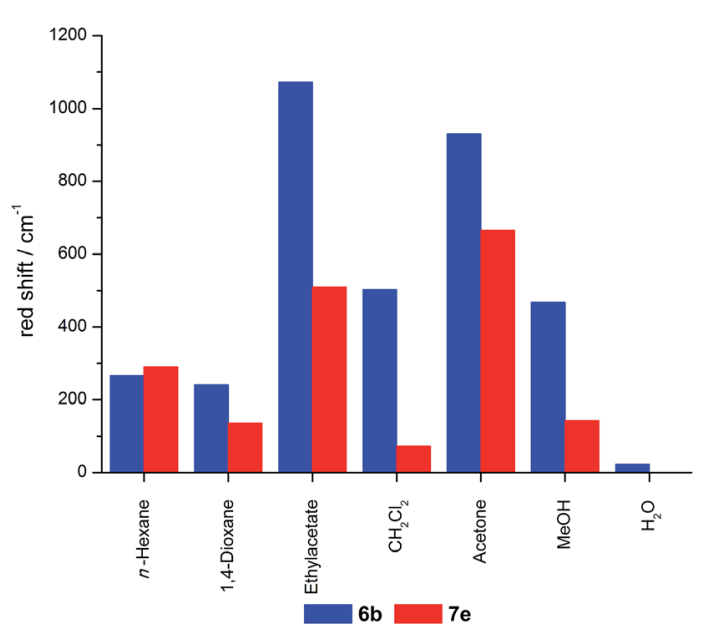

Fig. 15 REES of $6 \mathrm{~b}$ and 7e suspended in different solvents (range of excitation $n$-hexane: $3333 \mathrm{~cm}^{-1}, 1,4$-dioxane: $2389 \mathrm{~cm}^{-1}$, ethylacetate: $1374 \mathrm{~cm}^{-1}, \mathrm{CH}_{2} \mathrm{Cl}_{2}: 3607 \mathrm{~cm}^{-1}$, acetone: $3871 \mathrm{~cm}^{-1}, \mathrm{MeOH}$ : $4127 \mathrm{~cm}^{-1}, \mathrm{H}_{2} \mathrm{O}: 2309 \mathrm{~cm}^{-1}$ ).

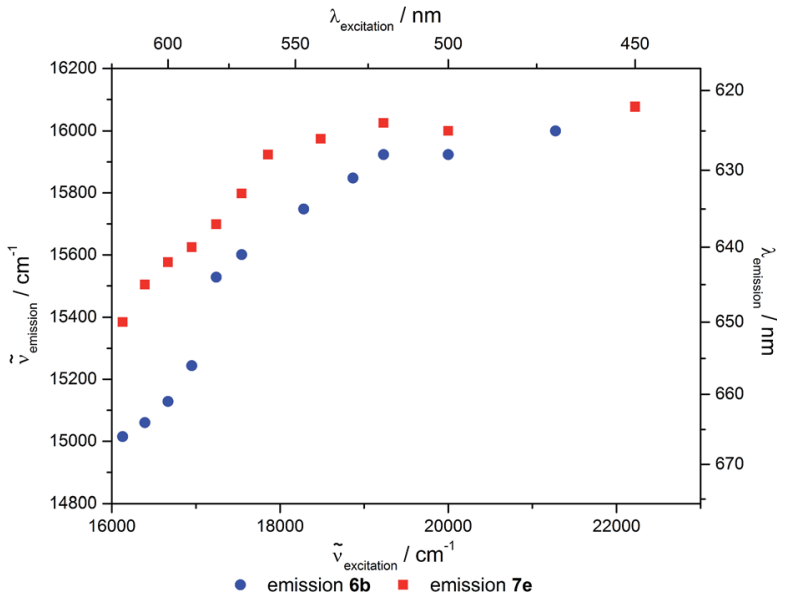

Fig. 16 REES of $6 \mathrm{~b}$ and $7 \mathrm{e}$ in acetone.

excitation in the red-edge a shift in the emission maxima can be observed.

As all grafted materials show a more pronounced REES it can be assumed that the distribution of dye molecules is more inhomogeneous. While some quite unrestricted molecules are located on the outside surface, some relatively restricted fluorophores reside inside the pore channels, and a fraction of molecules which is bound to the pore openings, where high dye concentrations are present, enhancing their restrain. In contrast, the relatively homogenous distribution inside the pores with only slight changes in the restriction of the molecules inside the channels could give rise to a less pronounced REES for the co-condensed materials.

\section{Fluorescence quenching}

For further investigation of the different hybrid materials fluorescence quenching experiments were conducted. Upon addition of hydrochloric acid to the water suspended hybrid materials $7 \mathbf{e}$ and $\mathbf{6 b}$, a decrease in fluorescence intensity can be monitored (Fig. 17).

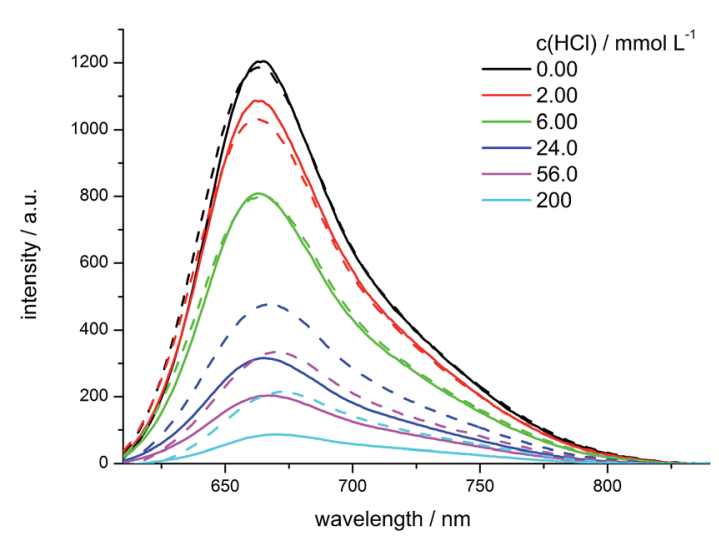

Fig. 17 Fluorescence spectra of water suspended hybrid materials 7e (solid lines) and $6 \mathrm{~b}$ (dashed lines) upon addition of $\mathrm{HCl}$ at the indicated concentrations. 
Both materials show an emission maximum at $664 \mathrm{~nm}$ with a small shoulder at $720-750 \mathrm{~nm}$ in the emissive state. Upon addition of an acid to the samples the emission maximum at $664 \mathrm{~nm}$ decreases and slightly shifts bathochromically to 670 $\mathrm{nm}$ for high acid concentrations. For the two materials with comparable dye loading levels of 1.5 and $1.9 \mu \mathrm{mol} \mathrm{g}{ }^{-1}$ the emission spectra at low acid concentrations (up to $6.00 \mathrm{mmol}$ $\mathrm{L}^{-1}$ ) look very similar. But upon further increase of the acid concentration, the co-condensed material $7 \mathbf{e}$ is more efficiently quenched than the grafted material $\mathbf{6 b}$. For the identical relative fluorescence intensity for the co-condensed hybrid 7e a smaller acid concentration is need than for the grafted hybrid $\mathbf{6 b}$ (Fig. 18). This indicates the presence of unequally distributed dye loading inside the different materials, which can also be observed in the plot of fluorescence intensities against acid concentrations.

In this Stern-Volmer plot the curves deviate from linearity with increasing acid concentrations towards the $x$-axis which is indicative for the presence of more than one species of fluorophores with variable accessibility to the quencher. These different classes of fluorophores can also be deduced from the excitation spectra of the quenched fluorophores (Fig. 19).

In the emissive state the different materials show slightly variable excitation maxima. For the co-condensed material 7e the maximum lies at $602 \mathrm{~nm}$, whereas the maximum of the grafted hybrid $\mathbf{6 b}$ is slightly shifted bathochromically to 608 $\mathrm{nm}$. Upon addition of $200 \mathrm{mmol} \mathrm{L}^{-1}$ of acid both materials show the same two excitation maxima at 588 and $640 \mathrm{~nm}$, but in the case of the grafted material $\mathbf{6 b}$ the signal at $640 \mathrm{~nm}$ is significantly more intense than in the co-condensed case $7 \mathbf{e}$. This newly arising redshifted excitation maximum at $640 \mathrm{~nm}$ corresponds to the literature known absorption maximum of $\mathrm{NR}-\mathrm{H}^{+} .{ }^{46,57}$

As the grafted materials show a more intense signal of the protonated NR species NR- $\mathrm{H}^{+}$than in the co-condensed case it can be assumed that the degree of $\mathrm{NR}-\mathrm{H}^{+}$is higher in the grafted hybrid $\mathbf{6 b}$ than in the co-condensed $7 \mathbf{e}$. This can be rationalized by preferred functionalization with the dye molecules on the outside surface and the pore openings of grafted materials

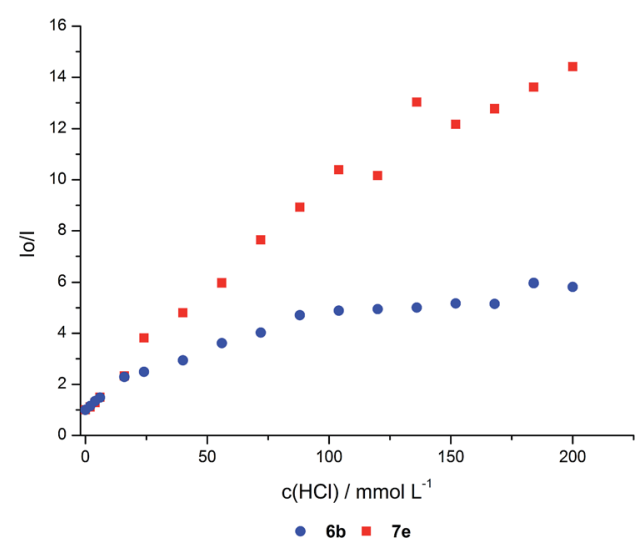

Fig. 18 Stern-Volmer plots of water suspended hybrid materials $6 \mathrm{~b}$ (blue circles) and $7 \mathrm{e}$ (red squares) upon addition of $\mathrm{HCl}$ at different concentrations.

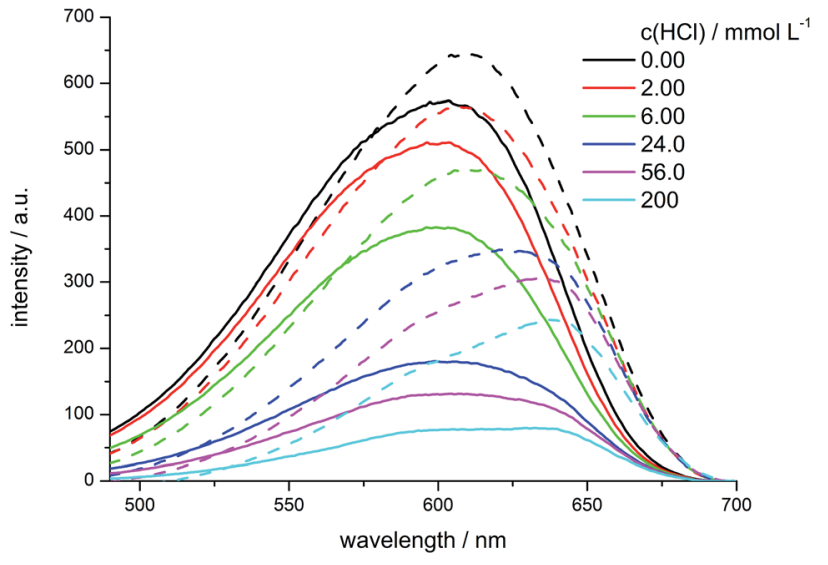

Fig. 19 Excitation spectra of water suspended hybrid materials $6 \mathrm{~b}$ (dashed lines) and $7 \mathrm{e}$ (solid lines) upon addition of $\mathrm{HCl}$ at the indicated concentrations $\left(\lambda_{\text {emission }}=720 \mathrm{~nm}\right.$ ).

enabling an easier protonation. In turn, in the co-condensed material the dye molecules are incorporated within the pores or even within the silica walls to a larger extent. In addition the surrounding silica matrix can act as a proton buffer.

\section{Conclusions}

The fluorescence dye 2-hydroxy NR was functionalized via propargylation and CuAAC reaction with an azido substituted triethoxysilane derivative to furnish a luminescent precursor for covalent ligation. The formation of mesoporous hybrid materials by incorporation into silica matrices with variable dye loading was accomplished by two synthetic approaches, i.e. by grafting onto a mesoporous MCM-41 host or by in situ co-condensation with concomitant formation of the mesoporous silica-dye hybrid. The structural and optical properties of these novel hybrids were thoroughly studied. Analysis of the materials by nitrogen sorption measurements in combination with SAXS and TEM confirmed a two-dimensional hexagonal columnar ordered mesoporous structure which is not affected by functionalization with the NR dye in the applied micromolar concentrations. Investigation of the optical properties revealed a red-edge excitation shift (REES) and fluorescence quenching, which were utilized to analyze the dye distribution inside the different materials. Therefore it can be qualitatively assumed that different dye species are present inside the grafted and co-condensed materials. While grafted materials are predominantly functionalized on the outside surface and in pore openings at high dye concentrations, the co-condensed materials obviously possess a more homogenous dye distribution and predominant functionalization inside the pores or silica walls. The hybrid materials retain, although much less pronounced, some optical characteristics of the NR, such as the solvatochromism. However, in contrast to the native dye, these synthesized hybrids possess quantum yields of about $20 \%$ in the solid state and even fluorescence in aqueous media which opens new alleys to applications of NR-based hybrid materials. Further studies directed to access novel functional 
organic hybrid materials by this approach are currently underway.

\section{Experimental}

\section{General considerations}

Reagents, catalyst and solvents were purchased reagent grade and used without further purification. Products were purified with column chromatography on silica gel $60(0.040-0.063 \mathrm{~mm})$ from M\&N using flash technique.

${ }^{1} \mathrm{H},{ }^{13} \mathrm{C}$ and 135 -DEPT NMR spectra were recorded on a Bruker AVIII-300 and the resonance of the particular solvent was locked as internal standard $\left(\mathrm{CDCl}_{3}:{ }^{1} \mathrm{H} \delta=7.26,{ }^{13} \mathrm{C} \delta=\right.$ 77.0, DMSO- $\left.\mathrm{d}_{6}:{ }^{1} \mathrm{H} \delta=2.50,{ }^{13} \mathrm{C} \delta=39.52\right)$. MALDI mass spectra were measured on a Bruker Daltronics Ultraflex I spectrometer, HR-ESI mass spectra were measured on a UHRQTOF maXis 4G Bruker Daltronics and GC mass spectra were obtained on a GCMS-QP2010 S spectrometer from Shimadzu. Combustion analyses were carried out on Elementar vario MICRO CUBE in the microanalytical laboratory of the Institut für Pharmazeutische und Medizinische Chemie at the Heinrich-Heine-Universität Düsseldorf. IR spectra were recorded on Shimadzu IRAffinity-1. Melting points were measured on a Büchi Melting Point B-540. $\mathrm{N}_{2}$-adsorption-desorption isotherms were determined at $77 \mathrm{~K}$ by a Quantachrome Nova 4200 e sorption analyser. Prior to the measurements the samples were degassed at $80.0{ }^{\circ} \mathrm{C}$ for $20 \mathrm{~h}$. Specific surface areas were calculated using the Brunauer-Emmett-Teller (BET) equation in the low pressure interval $p / p_{0}<0.3$. Pore size distributions were calculated from the adsorption branch using the non-local density function theory based on a slit-pore model. The total pore volume was calculated at the point of $p$ / $p_{0}=0.95$. X-ray diffraction data were collected on a Bruker AXS Nanostar C. The radiation source was a Siemens X-ray canal with a power of $1500 \mathrm{~W}$. The nickel-filtered monochromatic $\mathrm{Cu}_{\mathrm{K} \alpha 1}$ radiation wavelength of $1.5405 \mathrm{~nm}$ was maintained by using crossed Göbel mirrors as monochromator. Real-time detection was enabled using a Bruker HI-Star detector. Samples were measured in Hilgenberg glass capillaries with an outer diameter of $0.7 \mathrm{~nm}$. Pre-measurement calibration was carried out at $298 \mathrm{~K}$ with silver behenate as a standard reference. Data analysis was carried out using the following software: SAXS from Bruker, Datasqueeze (v. 2.2.8) from Heiney, QTIPlot (v.0.9.8) from Ion Vasilief and LCDiXray (v.1.0) from Golbert. Mesoporous structures were probed by HR-TEM at the institute of microstructure research in Jülich using a FEI TECNAI $\mathrm{G}^{2}$ operated at $200 \mathrm{kV}$. All HR-TEM samples were prepared by placing a drop of the hybrid material suspension in dichloromethane onto a carbon-coated grid at room temperature.

Excitation and emission spectra were recorded on a Hitachi F-7000 fluorescence spectrophotometer at $T=293 \mathrm{~K}$. Excitation of fluorescence was always carried out at the excitation maximum. Quantum yield determinations of the hybrid powders were obtained with an integrating sphere. Data analysis and quantum yield calculations were performed with the software FL Solutions Version 4.0 by Hitachi.

\section{Synthetic procedures}

(3-Azidopropyl)triethoxysilane ${ }^{58}$ (1). Sodium azide $(708 \mathrm{mg}$, $10.9 \mathrm{mmol})$ and sodium iodide (154 mg, $1.03 \mathrm{mmol}$ ) were placed in a Schlenk flask under nitrogen atmosphere and dissolved in DMSO $(10 \mathrm{~mL})$. Then (3-chloropropyl)triethoxysilane $(1.35 \mathrm{~g}, 5.61 \mathrm{mmol})$ was added and the solution was stirred at 60 ${ }^{\circ} \mathrm{C}$ for $18 \mathrm{~h}$. $n$-Hexane $(10 \mathrm{~mL})$ was added and the reaction mixture was stirred at room temp for $3 \mathrm{~h}$. The solution was washed with deionized water $(3 \times 5 \mathrm{~mL})$ and brine $(1 \times 5 \mathrm{~mL})$, and the organic layer was dried with anhydrous magnesium sulfate. The solvents were removed in vacuo and the residue was dried at $10^{-3}$ mbar for 4 days to give (3-azidopropyl)triethoxysilane $(1.03 \mathrm{~g}, 74 \%)$ as a colorless oil.

${ }^{1} \mathrm{H}$ NMR $\left(300 \mathrm{MHz}, \mathrm{CDCl}_{3}\right): \delta=0.64-0.71\left(\mathrm{~m}, 2 \mathrm{H},-\mathrm{SiCH}_{2}-\right)$, $1.23\left(\mathrm{t},{ }^{3} J_{\mathrm{HH}}=7.0 \mathrm{~Hz}, 9 \mathrm{H}, \mathrm{Si}\left(\mathrm{OCH}_{2} \mathrm{CH}_{3}\right)_{3}\right), 1.65-1.77(\mathrm{~m}, 2 \mathrm{H}$, $\left.-\mathrm{SiCH}_{2} \mathrm{CH}_{2}-\right), 3.26\left(\mathrm{t},{ }^{3} \mathrm{~J}_{\mathrm{HH}}=7.0 \mathrm{~Hz}, 2 \mathrm{H},-\mathrm{SiCH}_{2} \mathrm{CH}_{2} \mathrm{CH}_{2}-\right), 3.82$ $\left(\mathrm{q},{ }^{3} J_{\mathrm{HH}}=7.0 \mathrm{~Hz}, 6 \mathrm{H}, \mathrm{Si}\left(\mathrm{OCH}_{2} \mathrm{CH}_{3}\right)_{3}\right) \cdot{ }^{13} \mathrm{C} \mathrm{NMR}(75 \mathrm{MHz}$, $\left.\mathrm{CDCl}_{3}\right): \delta=7.6\left(\mathrm{CH}_{2}\right), 18.3\left(\mathrm{CH}_{3}\right), 22.7\left(\mathrm{CH}_{2}\right), 53.8\left(\mathrm{CH}_{2}\right), 58.5$ $\left(\mathrm{CH}_{2}\right)$. GC-MS: $m / z=163\left[\left(\mathrm{C}_{3} \mathrm{H}_{9} \mathrm{~N}_{3} \mathrm{O}_{3} \mathrm{Si}\right)^{+}\right], 119\left[\left(\mathrm{C}_{3} \mathrm{H}_{7} \mathrm{O}_{3} \mathrm{Si}\right)^{+}\right], 79$ $\left[(\mathrm{HO})_{3} \mathrm{Si}^{+}\right]$.

5-(Diethylamino)-2-nitrosophenol (2). ${ }^{32}$ 3-Diethylaminophenol (1) $(6.00 \mathrm{~g}, 36.1 \mathrm{mmol})$ was dissolved in a mixture of deionized water $(8 \mathrm{~mL})$ and concentrated hydrochloric acid $(14 \mathrm{~mL})$. The solution was cooled to $0{ }^{\circ} \mathrm{C}$ and a solution of sodium nitrite (2.49 $\mathrm{g}, 36.2 \mathrm{mmol})$ in deionized water $(20 \mathrm{~mL})$ was added dropwise over a period of $30 \mathrm{~min}$ and the stirring was continued at $0{ }^{\circ} \mathrm{C}$ for $4 \mathrm{~h}$. The solution was filtered and the residue recrystallized from ethanol $(100 \mathrm{~mL})$. After adding diethyl ether $(80 \mathrm{~mL})$ a brown solid precipitated and was filtered off. Drying at $50{ }^{\circ} \mathrm{C}$ and $10^{-3}$ mbar gave 5-(diethylamino)-2-nitrosophenol (2) (5.72 g, 81\%) as a brown solid.

${ }^{1} \mathrm{H}$ NMR (300 MHz, DMSO-d 6 ): $\delta=1.27\left(\mathrm{t},{ }^{3} J_{\mathrm{HH}}=7.1 \mathrm{~Hz}, 6 \mathrm{H}\right.$, $\left.-\mathrm{CH}_{3}\right), 3.82\left(\mathrm{~m}, 4 \mathrm{H},-\mathrm{CH}_{2}-\right), 6.75\left(\mathrm{~d},{ }^{3} J_{\mathrm{HH}}=2.2 \mathrm{~Hz}, 1 \mathrm{H}, 6-\mathrm{H}\right), 7.21$ $\left(\mathrm{dd},{ }^{3} J_{\mathrm{HH}}=10.4 \mathrm{~Hz}, J=2.2 \mathrm{~Hz}, 1 \mathrm{H}, 4-\mathrm{H}\right), 7.55\left(\mathrm{~d},{ }^{3} J_{\mathrm{HH}}=10.4 \mathrm{~Hz}\right.$, $1 \mathrm{H}, 3-\mathrm{H})$.

9-(Diethylamino)-2-hydroxy-5H-benz $[a]$ phenoxazin-5-one (3). ${ }^{31}$ A solution of 5-(diethylamino)-2-nitrosophenol (2) (1.00 g, $5.60 \mathrm{mmol})$ and 1,6-dihydroxynaphthalene $(0.75 \mathrm{~g}, 4.70 \mathrm{mmol})$ in DMF (90 mL) was heated to $155{ }^{\circ} \mathrm{C}$ for $4 \mathrm{~h}$. The solvent was removed in vacuo and the residue was purified by chromatography on silica gel ( $n$-hexane/ethyl acetate $1: 1$ ) to give 9(diethylamino)-2-hydroxy-5H-benz[a]phenoxazin-5-one (3) (8.66 $\mathrm{g}, 66 \%)$ as a violet solid, $\mathrm{Mp} 298{ }^{\circ} \mathrm{C}$.

${ }^{1} \mathrm{H}$ NMR (300 MHz, DMSO-d 6 ): $\delta=1.14\left(\mathrm{t},{ }^{3} J_{\mathrm{HH}}=7.0 \mathrm{~Hz}, 6 \mathrm{H}\right.$, $\left.-\mathrm{CH}_{3}\right), 3.45\left(\mathrm{q},{ }^{3} \mathrm{~J}_{\mathrm{HH}}=7.1 \mathrm{~Hz}, 4 \mathrm{H},-\mathrm{CH}_{2}-\right), 6.11(\mathrm{~s}, 1 \mathrm{H}, 6-\mathrm{H}), 6.57$ $\left(\mathrm{d},{ }^{4} J_{\mathrm{HH}}=2.6 \mathrm{~Hz}, 1 \mathrm{H}, 8-\mathrm{H}\right), 6.74\left(\mathrm{dd},{ }^{3} J_{\mathrm{HH}}=9.1 \mathrm{~Hz},{ }^{4} J_{\mathrm{HH}}=2.7\right.$ $\mathrm{Hz}, 1 \mathrm{H}, 10-\mathrm{H}), 7.07\left(\mathrm{dd},{ }^{3} J_{\mathrm{HH}}=8.6 \mathrm{~Hz},{ }^{4} J_{\mathrm{HH}}=2.5 \mathrm{~Hz}, 1 \mathrm{H}, 3-\mathrm{H}\right)$, $7.52\left(\mathrm{~d},{ }^{3} J_{\mathrm{HH}}=9.1 \mathrm{~Hz}, 1 \mathrm{H}, 11-\mathrm{H}\right), 7.85\left(\mathrm{~d},{ }^{4} J_{\mathrm{HH}}=2.4 \mathrm{~Hz}, 1 \mathrm{H}, 1-\right.$ $\mathrm{H}), 7.95\left(\mathrm{~d},{ }^{3} J_{\mathrm{HH}}=8.6 \mathrm{~Hz}, 1 \mathrm{H}, 4-\mathrm{H}\right), 10.41(\mathrm{~s}, 1 \mathrm{H},-\mathrm{OH}) .{ }^{13} \mathrm{C} \mathrm{NMR}$ (75 MHz, DMSO-d $\left.{ }_{6}\right): \delta=12.4\left(\mathrm{CH}_{3}\right), 44.4\left(\mathrm{CH}_{2}\right), 96.0(\mathrm{CH}), 104.0$ $(\mathrm{CH}), 108.1(\mathrm{CH}), 109.8(\mathrm{CH}), 118.3(\mathrm{CH}), 123.8\left(\mathrm{C}_{\text {quat }}\right), 127.4$ $(\mathrm{CH}), 130.7(\mathrm{CH}), 133.7$ ( $\left.\mathrm{C}_{\text {quat }}\right), 138.6$ ( $\left.\mathrm{C}_{\text {quat }}\right), 146.3$ ( $\left.\mathrm{C}_{\text {quat }}\right), 150.6$ ( $\left.\mathrm{C}_{\text {quat }}\right), 151.5$ (C $\left.\mathrm{C}_{\text {quat }}\right), 160.5\left(\mathrm{C}_{\text {quat }}\right), 181.5\left(\mathrm{C}_{\text {quat }}\right) . \mathrm{IR}: \tilde{\nu} / \mathrm{cm}^{-1}=$ $638(\mathrm{~m}), 671(\mathrm{~m}), 687(\mathrm{~m}), 702(\mathrm{~m}), 745(\mathrm{~m}), 783(\mathrm{~m}), 797(\mathrm{~m})$, $818(\mathrm{~m}), 847(\mathrm{~m}), 887(\mathrm{~m}), 910(\mathrm{~m}), 953(\mathrm{~m}), 1013(\mathrm{~m}), 1028(\mathrm{~m})$, 1028 (m), 1045 (m), 1074 (m), 1112 (vs), 1150 (m), 1159 (m), 1180 
(m), 1221 (m), 1258 (vs), 1288 (m), 1317 (vs), 1377 (m), 1406 (m), 1439 (m), 1474 (m), 1485 (m), 1505 (m), 1520 (m), 1537 (m), 1562 (m), 2625 (br), 2870 (w), 2924 (w), 2963 (w), 3046 (br). HR-MS (ESI) calcd for $\left(\mathrm{C}_{20} \mathrm{H}_{18} \mathrm{~N}_{2} \mathrm{O}_{3}+\mathrm{H}\right)^{+}: m / z=335.13902(100 \%)$, 336.14237 (22\%); found: 335.13893 (100\%), 336.14204 (15\%). Anal. calcd for $\mathrm{C}_{20} \mathrm{H}_{18} \mathrm{~N}_{2} \mathrm{O}_{3}$ (334.4): $\mathrm{C}$ 71.84, $\mathrm{H}$ 5.43, N 8.38; found: C 71.66, H 5.52, N 8.09.

9-(Diethylamino)-2-(prop-2-yn-1-yloxy)-5H-benzo[a]phenoxazin-5-one (4). 9-(Diethylamino)-2-hydroxy-5H-benz $[a]$ phenoxazin5-one (3) (334 mg, $1.00 \mathrm{mmol}$ ) and potassium carbonate $(280 \mathrm{mg}$, $2.00 \mathrm{mmol}$ ) were dissolved in DMF $(5 \mathrm{~mL})$. To this solution propargyl bromide (145 $\mathrm{mg}, 1.22 \mathrm{mmol}$ ) was added and the mixture was stirred at $80{ }^{\circ} \mathrm{C}$ for $16 \mathrm{~h}$. The reaction mixture was diluted with diethyl ether $(25 \mathrm{~mL})$ and brine $(25 \mathrm{~mL})$. The organic layer was separated and the aqueous layer washed with diethyl ether $(3 \times 25 \mathrm{~mL})$. The combined organic layers were dried with anhydrous magnesium sulfate and the solvents were removed in vacuo. The residue was adsorbed on Celite and purified by chromatography on silica gel ( $n$-hexane/ethyl acetate $2: 1$, with $5 \%$ triethylamine) to give compound 4 as a red solid (89.0 mg, 24\%), Mp 192-194 ${ }^{\circ} \mathrm{C}$.

${ }^{1} \mathrm{H}$ NMR $\left(300 \mathrm{MHz}, \mathrm{CDCl}_{3}\right): \delta=1.25\left(\mathrm{t},{ }^{3} J_{\mathrm{HH}}=7.1 \mathrm{~Hz}, 6 \mathrm{H}\right.$, $\left.-\mathrm{NCH}_{2} \mathrm{CH}_{3}\right), 2.58\left(\mathrm{t},{ }^{4} J_{\mathrm{HH}}=2.4 \mathrm{~Hz}, 2 \mathrm{H},-\mathrm{OCH}_{2} \mathrm{CCH}\right), 3.45\left(\mathrm{q},{ }^{3} J_{\mathrm{HH}}\right.$ $\left.=7.1 \mathrm{~Hz}, 4 \mathrm{H},-\mathrm{NCH}_{2} \mathrm{CH}_{3}\right), 4.88\left(\mathrm{t},{ }^{4} J_{\mathrm{HH}}=2.4 \mathrm{~Hz}, 1 \mathrm{H},-\mathrm{OCH}_{2}-\right)$, $6.28(\mathrm{~s}, 1 \mathrm{H}, 6-\mathrm{H}), 6.42\left(\mathrm{~d},{ }^{4} J_{\mathrm{HH}}=2.6 \mathrm{~Hz}, 1 \mathrm{H}, 8-\mathrm{H}\right), 6.62\left(\mathrm{dd},{ }^{3} J_{\mathrm{HH}}=\right.$ $\left.9.1 \mathrm{~Hz},{ }^{4} J_{\mathrm{HH}}=2.6 \mathrm{~Hz}, 1 \mathrm{H}, 10-\mathrm{H}\right), 7.22\left(\mathrm{dd},{ }^{3} J_{\mathrm{HH}}=8.7 \mathrm{~Hz},{ }^{4} J_{\mathrm{HH}}=\right.$ $2.6 \mathrm{~Hz}, 1 \mathrm{H}, 3-\mathrm{H}), 7.57\left(\mathrm{~d},{ }^{3} \mathrm{~J}_{\mathrm{HH}}=9.1 \mathrm{~Hz}, 1 \mathrm{H}, 11-\mathrm{H}\right), 8.10\left(\mathrm{~d},{ }^{4} J_{\mathrm{HH}}=\right.$ $2.6 \mathrm{~Hz}, 1 \mathrm{H}, 1-\mathrm{H}), 8.23$ (d, $\left.{ }^{3} \mathrm{~J}_{\mathrm{HH}}=8.7 \mathrm{~Hz}, 1 \mathrm{H}, 4-\mathrm{H}\right) .{ }^{13} \mathrm{C} \mathrm{NMR}(75$ $\left.\mathrm{MHz}, \mathrm{CDCl}_{3}\right): \delta=12.6\left(\mathrm{CH}_{3}\right), 45.1\left(\mathrm{CH}_{2}\right), 56.1\left(\mathrm{CH}_{2}\right), 96.3(\mathrm{CH})$, $105.3(\mathrm{CH}), 107.2(\mathrm{CH}), 109.6(\mathrm{CH}), 118.4(\mathrm{CH}), 124.8\left(\mathrm{C}_{\text {quat }}\right)$, $126.4\left(\mathrm{C}_{\text {quat }}\right), 127.9(\mathrm{CH}), 131.2(\mathrm{CH}), 134.0\left(\mathrm{C}_{\text {quat }}\right), 139.8\left(\mathrm{C}_{\text {quat }}\right)$, 146.8 ( $\left.\mathrm{C}_{\text {quat }}\right), 150.8$ ( $\left.\mathrm{C}_{\text {quat }}\right), 152.1$ ( $\left.\mathrm{C}_{\text {quat }}\right), 160.1$ ( $\left.\mathrm{C}_{\text {quat }}\right), 183.1$ (C $\left.\mathrm{C}_{\text {quat }}\right)$. IR: $\tilde{\nu} / \mathrm{cm}^{-1}=679(\mathrm{~m}), 591(\mathrm{~m}), 704(\mathrm{~m}), 743(\mathrm{~m}), 756(\mathrm{~m})$, $789(\mathrm{~m}), 807$ (m), 820 (s), 845 (m), 864 (m), 880 (m), 893 (m), 924 (m), 1005 (s), $1034(\mathrm{~m}), 1080$ (s), 1115 (s), 1150 (m), 1179 (m), 1194 (m), 1207 (m), 1250 (s), 1267 (s), 1292 (m), 1315 (m), 1335 (m), 1373 (m), 1404 (s), 1454 (m), 1468 (m), 1491 (m), 1518 (w), 1530 (w), 1555 (m), 1572 (m), 1589 (s), 1638 (w), 1687 (w), $1726(\mathrm{~m})$, 2106 (w), 2332 (w), 2359 (w), $2872(\mathrm{w}), 2928(\mathrm{~m}), 2959(\mathrm{~m}), 3194$ (m). MALDI-TOF: $m / z=373.4\left(\mathrm{C}_{23} \mathrm{H}_{20} \mathrm{~N}_{2} \mathrm{O}_{3}+\mathrm{H}\right)^{+}$.

9-(Diethylamino)-2-((1-(3-(triethoxysilyl)propyl)-1H-1,2,3-triazol-4-yl)methoxy)-5H-benzo[a]phenoxazin-5-one (5). 9-(Diethylamino)-2-(prop-2-yn-1-yloxy)-5 $H$-benzo[ $a]$ phenoxa-zin-5-one
(80.0 $\mathrm{mg}, 0.210 \mathrm{mmol}$ ), copper sulfate pentahydrate $(12.0 \mathrm{mg}$, $0.0500 \mathrm{mmol})$ and sodium ascorbate $(20.0 \mathrm{mg}, 0.100 \mathrm{mmol})$ were dissolved in DMF $(1 \mathrm{~mL})$. Then a solution of (3-azidopropyl)triethoxysilane (270 $\mathrm{mg}, 1.90 \mathrm{mmol}$ ) in DMF ( $2 \mathrm{~mL}$ ) was added and the mixture was stirred at $40{ }^{\circ} \mathrm{C}$ for $13 \mathrm{~h}$. Then diethyl ether (50 $\mathrm{mL})$ and brine $(20 \mathrm{~mL})$ were added to the solution and the aqueous layer was washed with diethyl ether $(4 \times 50 \mathrm{~mL})$. The combined organic layers were dried with anhydrous magnesium sulfate and the solvent was removed in vacuo. The residue was purified by chromatography on silica gel ( $n$-hexane/ethyl acetate $1: 1)$ to give compound 5 as a red solid $(60.0 \mathrm{mg}, 45 \%)$.

${ }^{1} \mathrm{H}$ NMR $\left(300 \mathrm{MHz}, \mathrm{CDCl}_{3}\right): \delta=0.61\left(\mathrm{~m}, 2 \mathrm{H},-\mathrm{NCH}_{2} \mathrm{CH}_{2}-\right.$ $\left.\mathrm{CH}_{2} \mathrm{Si}-\right), 1.24\left(\mathrm{~m}, 15 \mathrm{H}, \mathrm{Si}\left(\mathrm{OCH}_{2} \mathrm{CH}_{3}\right)_{3},-\mathrm{NCH}_{2} \mathrm{CH}_{3}\right), 2.05(\mathrm{~m}, 2 \mathrm{H}$, $-\mathrm{NCH}_{2} \mathrm{CH}_{2} \mathrm{CH}_{2} \mathrm{Si}-$ ), 3.47 (q, $\left.{ }^{3} J_{\mathrm{HH}}=7.1 \mathrm{~Hz}, 4 \mathrm{H},-\mathrm{NCH}_{2} \mathrm{CH}_{3}\right), 3.80$ $\left(\mathrm{q}, 6 \mathrm{H}, \mathrm{Si}\left(\mathrm{OCH}_{2} \mathrm{CH}_{3}\right)_{3}\right), 4.39\left(\mathrm{t},{ }^{3} J_{\mathrm{HH}}=7.2 \mathrm{~Hz}, 2 \mathrm{H},-\mathrm{NCH}_{2} \mathrm{CH}_{2}-\right.$ $\left.\mathrm{CH}_{2} \mathrm{Si}-\right)$, $5.42\left(\mathrm{~s}, 2 \mathrm{H},-\mathrm{OCH}_{2} \mathrm{C}-\right), 6.30(\mathrm{~s}, 1 \mathrm{H}, 6-\mathrm{H}), 6.45\left(\mathrm{~d},{ }^{4} J_{\mathrm{HH}}=\right.$ $2.6 \mathrm{~Hz}, 1 \mathrm{H}, 8-\mathrm{H}), 6.66\left(\mathrm{dd},{ }^{3} J_{\mathrm{HH}}=9.1 \mathrm{~Hz},{ }^{4} J_{\mathrm{HH}}=2.7 \mathrm{~Hz}, 1 \mathrm{H}, 10-\right.$ $\mathrm{H}), 7.23\left(\mathrm{dd},{ }^{3} J_{\mathrm{HH}}=8.7 \mathrm{~Hz},{ }^{4} J_{\mathrm{HH}}=2.5 \mathrm{~Hz}, 1 \mathrm{H}, 3-\mathrm{H}\right), 7.60\left(\mathrm{~d},{ }^{3} J_{\mathrm{HH}}\right.$ $=9.1 \mathrm{~Hz}, 1 \mathrm{H}, 11-\mathrm{H}), 7.69(\mathrm{~s}, 1 \mathrm{H},-\mathrm{CCHN}-), 8.18\left(\mathrm{~d},{ }^{4} J_{\mathrm{HH}}=2.5\right.$ $\mathrm{Hz}, 1 \mathrm{H}, 1-\mathrm{H}), 8.23\left(\mathrm{~d},{ }^{3} J_{\mathrm{HH}}=8.7 \mathrm{~Hz}, 1 \mathrm{H}, 4-\mathrm{H}\right) .{ }^{13} \mathrm{C} \mathrm{NMR}(75 \mathrm{MHz}$, $\left.\mathrm{CDCl}_{3}\right): \delta=7.47\left(\mathrm{CH}_{2}\right), 12.6\left(\mathrm{CH}_{3}\right), 18.3\left(\mathrm{CH}_{3}\right), 24.2\left(\mathrm{CH}_{2}\right), 45.1$ $\left(\mathrm{CH}_{2}\right), 52.6\left(\mathrm{CH}_{2}\right), 58.5\left(\mathrm{CH}_{2}\right), 62.5\left(\mathrm{CH}_{2}\right), 96.3(\mathrm{CH}), 105.3(\mathrm{CH})$, $106.9(\mathrm{CH}), 109.6(\mathrm{CH}), 118.4(\mathrm{CH}), 122.8(\mathrm{CH}), 124.8\left(\mathrm{C}_{\text {quat }}\right)$, 126.1 ( $\left.\mathrm{C}_{\text {quat }}\right), 127.9(\mathrm{CH}), 131.2(\mathrm{CH}), 134.1$ ( $\left.\mathrm{C}_{\text {quat }}\right), 139.8\left(\mathrm{C}_{\text {quat }}\right)$, 143.5 ( $\mathrm{C}_{\text {quat }}$ ), 146.9 ( $\left.\mathrm{C}_{\text {quat }}\right), 150.8$ (C $\left.\mathrm{C}_{\text {quat }}\right), 152.1$ ( $\left.\mathrm{C}_{\text {quat }}\right), 160.9$ $\left(\mathrm{C}_{\text {quat }}\right), 183.2\left(\mathrm{C}_{\text {quat }}\right) . \mathrm{IR}: \tilde{\nu} / \mathrm{cm}^{-1}=638(\mathrm{~m}), 669(\mathrm{~m}), 683(\mathrm{~m}), 716$ (m), $789(\mathrm{~s}), 818(\mathrm{~s}), 881(\mathrm{~m}), 910(\mathrm{~m}), 953(\mathrm{~m}), 1011(\mathrm{~m}), 1030$ (m), 1072 (vs), 1111 (vs), 1161 (m), 1182 (m), 1194 (m), 1223 (m), 1256 (s), 1271 (s), 1314 (s), 1346 (m), 1406 (s), 1439 (m), 1458 (m), 1470 (m), 1479 (m), 1497 (m), 1520 (m), 1558 (m), 1582 (vs), 1620 (m), 1641 (m), 1670 (w), 1680 (w), 2891 (w), 2928 (w), 2972 (w), $3084(\mathrm{w}), 3134(\mathrm{w})$. HR-MS (ESI) calcd for $\left(\mathrm{C}_{32} \mathrm{H}_{41} \mathrm{~N}_{5} \mathrm{O}_{6} \mathrm{Si}+\right.$ $\mathrm{H})^{+}: \quad m / z=620.28989$; found: 620.28975; calcd for $\left(\mathrm{C}_{26} \mathrm{H}_{29} \mathrm{~N}_{5} \mathrm{O}_{6} \mathrm{Si}+\mathrm{H}\right)^{+}: m / z=536.19599$; found: 536.19595 .

\section{Synthesis of hybrid materials}

Grafted NR MCM hybrids (6a-f). Six NR-functionalized silica hybrid materials were synthesized by postsynthetic grafting. For employing small amounts of the precursor 5 four different stock solutions of $c_{1}(5)=49.0 \mu \mathrm{M}, c_{2}(5)=0.610 \mathrm{mM}$ and $c_{3}(5)=$ $5.00 \mathrm{mM}, c_{4}(5)=5.72 \mathrm{mM}$ in ethanol were prepared. The solution of dye 5, MCM-41, and ethanol were subsequently

Table 5 Experimental details of the synthesis of NR grafted MCM-41 hybrid materials 6

\begin{tabular}{lllllll}
\hline Sample & $\begin{array}{l}\text { Applied loading of } \\
\text { hybrid with } \mathbf{5}\left[\mu \mathrm{mol} \mathrm{g}^{-1}\right]\end{array}$ & $\begin{array}{l}\text { Determined loading of } \\
\text { hybrid with } \mathbf{5}\left[\mu \mathrm{mol} \mathrm{g}^{-1}\right]\end{array}$ & $\begin{array}{l}\text { Volume of stock } \\
\text { solution }[\mathrm{mL}]\end{array}$ & $\begin{array}{l}\text { Mass of } \\
\text { MCM-41 }[\mathrm{g}]\end{array}$ & $\begin{array}{l}\text { Volume of } \\
\text { ethanol }[\mathrm{mL}]\end{array}$ & $\begin{array}{l}\text { Yield of NR grafted } \\
\text { MCM-41 hybrid materials } \mathbf{6}[\mathrm{g}]\end{array}$ \\
\hline $\mathbf{6 a}$ & 1.0 & 0.6 & 8.91 of $c_{1}(\mathbf{5})$ & 0.437 & 6.10 & 0.408 \\
$\mathbf{6 b}$ & 2.5 & 1.5 & 0.50 of $c_{3}(\mathbf{5})$ & 1.00 & 14.5 & 0.560 \\
$\mathbf{6 c}$ & 5.0 & 2.9 & 14.3 of $c_{2}(\mathbf{5})$ & 1.75 & 0.70 & 1.64 \\
$\mathbf{6 d}$ & 10 & 5.9 & 2.00 of $c_{3}(\mathbf{5})$ & 1.00 & 13.0 & 0.624 \\
$\mathbf{6 e}$ & 15 & 8.8 & 3.00 of $c_{3}(5)$ & 1.00 & 12.0 & 0.752 \\
$\mathbf{6 f}$ & 20 & 12 & 3.50 of $c_{4}(\mathbf{5})$ & 1.00 & 11.5 & 0.802 \\
$\mathbf{6 g}$ & 20 & 12 & 14.3 of $c_{2}(5)$ & 0.437 & 0.70 & 0.396 \\
$\mathbf{6 h}$ & 30 & 18 & 5.24 of $c_{4}(5)$ & 1.00 & 9.76 & 0.804 \\
$\mathbf{6 i}$ & 40 & 23 & 6.99 of $c_{4}(\mathbf{5})$ & 1.00 & 8.01 & 0.892
\end{tabular}


added to the reaction vessel and stirred at room temp for $20 \mathrm{~h}$, followed by stirring at $80{ }^{\circ} \mathrm{C}$ for $24 \mathrm{~h}$ (for experimental details, see Table 5). The obtained suspensions were centrifuged (10 min, $4000 \mathrm{rpm})$, decanted and resuspended in ethanol $(20 \mathrm{~mL})$ and $2 \mathrm{M}$ aqueous hydrochloric acid solution $(1 \mathrm{~mL})$, upon which the red suspensions turned blue. After heating to $80{ }^{\circ} \mathrm{C}$ for $24 \mathrm{~h}$ the reaction mixtures were centrifuged, the solids transferred into a Soxhlet extraction thimble and extracted with ethanol over a period of $48 \mathrm{~h}$. The obtained powders were washed with triethylamine $(2 \mathrm{~mL})$ and ethanol $(20 \mathrm{~mL})$, which led to a color change back to red. The solids were washed with ethanol $(3 \times 20 \mathrm{~mL})$ and centrifuged each time as described until the supernatant reached $\mathrm{pH}$ 7. The obtained violet powders were dried at $60^{\circ} \mathrm{C}$ and $10^{-3}$ mbar for 3 days to mass constancy.

Co-condensed NR MCM-hybrids $(7 \mathbf{a}-\mathbf{h}) \cdot{ }^{43}$ For the synthesis of the co-condensed NR-functionalized silica hybrids a solution of tetraethyl orthosilicate (TEOS), variable amounts of precursor $\mathbf{5}$, hexadecyl-trimethyl-ammonium bromide $\left(\mathrm{C}_{16} \mathrm{TMABr}\right)$, ethylamine, methanol, and deionized water was prepared with molar ratios of $1.00: x: 0.140: 2.40: 2.00: 100$ (molar ratios $x$ of precursor 5 are given in Table 6). First the template $\mathrm{C}_{16} \mathrm{TMABr}$ was dissolved in deionized water and ethylamine, which was employed as a $70 \mathrm{wt} \%$ aqueous solution before TEOS and the molar amount $x$ of precursor 5 in methanol were added. For the syntheses of materials $\mathbf{7 f}-\mathbf{h} 10$ molar equivalents of methanol were used. The mixtures were stirred at room temperature for 24 $\mathrm{h}$ with a speed of $750 \mathrm{rpm}$ before they were heated to $100{ }^{\circ} \mathrm{C}$ for $24 \mathrm{~h}$. The obtained suspensions were centrifuged (10 min, 4000 rpm), decanted and washed with ethanol before they were centrifuged again. Then the residues were suspended in ethanol $(80 \mathrm{~mL})$ and concentrated aqueous hydrochloric acid solution (2 $\mathrm{mL}$ ) and stirred at $80^{\circ} \mathrm{C}$ for $24 \mathrm{~h}$. The mixtures were centrifuged, and the solids were transferred into a Soxhlet extraction thimble and extracted with ethanol over a period of $48 \mathrm{~h}$. The obtained powders were washed once with triethylamine $(2 \mathrm{~mL})$ and ethanol $(80 \mathrm{~mL})$ upon which they turned red again. The solids were washed with ethanol $(3 \times 80 \mathrm{~mL})$ and centrifuged as described above till the supernatant reached $\mathrm{pH}$ 7. The obtained violet powders were dried at $60{ }^{\circ} \mathrm{C}$ and $10^{-3}$ mbar for 3 days to mass constancy.

Table 6 Experimental details of the synthesis of co-condensed NR hybrid materials 7

\begin{tabular}{lllll}
\hline & $\begin{array}{l}\text { Applied } \\
\text { loading } \\
\text { of hybrid with } \\
\mathbf{5}\left[\mu \mathrm{mol} \mathrm{g}^{-1}\right]\end{array}$ & $\begin{array}{l}\text { Determined } \\
\text { loading of } \\
\text { hybrid with } \\
\mathbf{5}\left[\mu \mathrm{mol} \mathrm{g}^{-1}\right]\end{array}$ & $\begin{array}{l}\text { Molar ratio } x \\
\text { of precursor } \mathbf{5}\end{array}$ & $\begin{array}{l}\text { Yield of } \\
\text { co-condensed } \\
\text { NR hybrid } \\
\text { materials } 7[\mathrm{~g}]\end{array}$ \\
\hline Sample & & & \\
\hline $\mathbf{7 a}$ & 0.1 & 0.04 & $2.08 \times 10^{-5}$ & 2.23 \\
$\mathbf{7 b}$ & 0.5 & 0.2 & $1.04 \times 10^{-4}$ & 2.01 \\
$\mathbf{7 c}$ & 1.0 & 0.4 & $2.08 \times 10^{-4}$ & 2.86 \\
$\mathbf{7 d}$ & 2.5 & 0.9 & $5.20 \times 10^{-4}$ & 2.83 \\
$\mathbf{7 e}$ & 5.0 & 1.9 & $1.04 \times 10^{-3}$ & 2.87 \\
$\mathbf{7 f}$ & 20 & 7.4 & $4.16 \times 10^{-3}$ & 1.23 \\
$\mathbf{7 g}$ & 40 & 11 & $6.24 \times 10^{-3}$ & 1.47 \\
$\mathbf{7 h}$ & 30 & 15 & $8.32 \times 10^{-3}$ & 1.41
\end{tabular}

\section{Acknowledgements}

The authors cordially thank the Strategic Research Fund of the Heinrich Heine University, the Deutsche Forschungsgemeinschaft DFG (Mu 1088/9-1), and the Fonds der Chemischen Industrie for financial support. Furthermore we thank Dr Juri Barthel and the Ernst Ruska-Centre (ER-C) for help and access to the HR-TEM facilities.

\section{Notes and references}

1 C. T. Kresge, M. E. Lenowicz, W. J. Roth, J. C. Vartuli and J. S. Beck, Nature, 1992, 359, 710.

2 C. T. Kresge, J. C. Vartuli, W. J. Roth and M. E. Leonowicz, Stud. Surf. Sci. Catal., 2004, 148, 53.

3 C. T. Kresge and W. J. Roth, Chem. Soc. Rev., 2013, 42, 3663. 4 A. Taguchi and F. Schüth, Microporous Mesoporous Mater., 2005, 77, 1 .

5 A. B. Descalzo, M. D. Marcos, C. Monte, R. Martínez-Máñez and K. Rurack, J. Mater. Chem., 2007, 17, 4716.

6 G. Wirnsberger, B. J. Scott and G. D. Stucky, Chem. Commun., 2001, 119.

7 F. Marlow, M. D. McGehee, D. Zhao, B. F. Chmelka and G. D. Stucky, Adv. Mater., 1999, 11, 632.

8 N. Vadia and S. Rajput, Asian J. Pharm. Clin. Res., 2011, 4, 44. 9 V. Mameava, C. Sahlgren and M. Lindén, Adv. Drug Delivery Rev., 2013, 65, 689.

10 J. M. Rosenholm, C. Sahlgren and M. Lindén, Nanoscale, 2010, 2, 1870.

11 Y.-S. Lin, C.-P. Tsai, H.-Y. Huang, C.-T. Kuo, Y. Hung, D.-M. Huang, Y.-C. Chen and C.-Y. Mou, Chem. Mater., 2005, 17, 4570.

12 F. Hoffmann, M. Cornelius, J. Morell and M. Fröba, Angew. Chem., Int. Ed., 2006, 45, 3216.

13 M. Sharifi, R. Marschall, M. Wilhelm, D. Wallacher and M. Wark, Langmuir, 2011, 27, 5516.

14 N. Gartmann and D. Brühwiler, Angew. Chem., Int. Ed., 2009, 45, 6354.

15 D. Aiello, R. Aiello, F. Testa, T. Martino, I. Aiello, M. La Deda and M. Ghedini, J. Photochem. Photobiol., A, 2009, 201, 81.

16 C. M. Carbonaro, R. Corpino, P. C. Ricci, D. Chiriu and C. Cannas, AIP Conf. Proc., 2014, 1624, 23.

17 G. Schulz-Ekloff, D. Wöhrle, B. van Duffel and R. A. Schoonheydt, Microporous Mesoporous Mater., 2002, 51, 91.

18 D. Aiello, A. M. Talarico, F. Teocoli, E. I. Szerb, I. Aiello, F. Testa and M. Ghedini, New J. Chem., 2011, 35, 141.

19 Q. He, J. Shi, X. Cui, J. Zhao, Y. Chen and J. Zhou, J. Mater. Chem., 2009, 19, 3395.

20 P. Greenspan, E. P. Mayer and S. D. Fowler, J. Cell Biol., 1985, $100,965$.

21 N. N. Alekseev, SU 1109 393, 1983.

22 H. Tajalli, A. G. Gilani, M. S. Zakerhamidi and P. Tajalli, Dyes Pigm., 2008, 78, 15.

23 J. L. Meinershagen and T. Bein, J. Am. Chem. Soc., 1999, 121, 448.

24 G. Hungerford and J. A. Ferreira, J. Lumin., 2001, 93, 155. 
25 J. Jose and K. Burgess, J. Org. Chem., 2006, 71, 7835.

26 J. Jose, A. Loudet, Y. Ueno, R. Barhoumi, R. C. Burghardt and K. Burgess, Org. Biomol. Chem., 2010, 8, 2052.

27 T. Behnke, C. Würth, K. Hoffmann, M. Hübner, U. Panne and U. Resch-Genger, J. Fluoresc., 2011, 21, 937.

28 T. Felbeck, T. Behnke, K. Hoffmann, M. Grabolle, M. M. Lezhina, U. H. Kynast and U. Resch-Genger, Langmuir, 2013, 29, 11489.

29 J. Qian, X. Li, M. Wie, X. Gao, Z. Xu and S. He, Opt. Express, 2008, 16, 19568.

30 R. Sastre and A. Costela, Adv. Mater., 1995, 7, 198.

31 S.-Y. Park, Y. Kubota, K. Funabiki, M. Shiro and M. Matsui, Tetrahedron Lett., 2009, 50, 1131.

32 S. A. Martin-Brown, Y. Fu, G. Saroja, M. M. Collinson and D. A. Higgins, Anal. Chem., 2005, 77, 486.

33 M. Meldal and C. W. Tornoe, Chem. Rev., 2008, 108, 2952.

34 M. Berchel, J.-P. Haelters, D. Afonso, A. Maroto, L. Deschaps, P. Giamarchi and P.-A. Jaffrès, Eur. J. Org. Chem., 2014, 1076.

35 K. S. W. Sing, D. H. Everett, R. A. W. Haul, L. Moscou, R. A. Pierotti, J. Rouquérol and T. Siemieniewska, Pure Appl. Chem., 1985, 57, 603.

36 M. Kruk and M. Jaroniec, Chem. Mater., 2001, 13, 3169.

37 H.-P. Lin, S.-T. Wong, C.-Y. Mou and C.-Y. Tang, J. Phys. Chem. B, 2000, 104, 8967.

38 D. Zhao, Y. Wan and W. Zhou, Ordered Mesoporous Materials, Wiley-VCH GmbH \& Co. KGaA, Weinheim, 2013.

39 G. A. Tompsett, L. Krogh, D. W. Griffin and W. C. Conner, Langmuir, 2005, 21, 8214.

40 P. Cool, E. F. Vasant and O. Collart, in Inorganic Chemistry in Focus II, ed. G. Meyer, D. Naumann and L. Wesemann, Wiley, Weinheim, 2005, p. 319.

41 M. T. Anderson, J. E. Martin, J. G. Odinek and P. P. Newcomer, Chem. Mater., 1998, 10, 1490.
42 S. Liu, P. Cool, O. Collart, P. van der Voort, E. F. Vasant, O. I. Lebedev, G. van Tendeloo and M. Jiang, J. Phys. Chem. $B, 2003,107,10405$.

43 Z. Zhou, A. W. Franz, S. Bay, B. Sarkar, A. Seifert, P. Yang, A. Wagener, S. Ernst, M. Pagels, T. J. J. Müller and W. R. Thiel, Chem.-Asian J., 2010, 5, 2001.

44 K. J. Edler, in Porous Materials, ed. D. W. Bruce, D. O'Hare and R. I. Walton, John Wiley \& Sons, Ltd, Chinchester, 2011, p. 108.

45 M. L. Hair and W. Hertl, J. Phys. Chem., 1970, 74, 91.

46 E. M. Moreno and D. Levy, Chem. Mater., 2000, 12, 2334.

47 J. R. Lakowicz, Principles of Fluorescence Spectroscopy, Springer, Baltimore, 3rd edn, 2006.

48 A. P. Demchenko, Luminescence, 2002, 17, 19.

49 S. Mukherjee, H. Raghuraman and A. Chattopadhyay, Biochim. Biophys. Acta, 2007, 59.

50 R. Saxena, S. Shrivastava, S. Haldar, A. S. Klymchenko and A. Chattopadhyay, Chem. Phys. Lipids, 2014, 183, 1.

51 E. Fleige, B. Ziem, M. Grabolle, R. Haag and U. ReschGenger, Macromolecules, 2012, 45, 9452.

52 T. Behnke, C. Würth, E.-M. Laux, K. Hoffmann and U. ReschGenger, Dyes Pigm., 2012, 94, 247.

53 R. Varghese and H.-A. Wagenknecht, Chem.-Eur. J., 2010, 16, 9040.

54 C. Martín, P. Piatowski, B. Cohen, M. Cil, M. T. Navarro, A. Corma and A. Douhal, J. Phys. Chem. C, 2015, 119, 13283.

55 F. Würthner, T. E. Kaiser and C. R. Saha-Möller, Angew. Chem., Int. Ed., 2011, 50, 3376.

56 J. Mei, Y. Hong, J. W. Y. Lam, A. Qin, Y. Tang and B. Z. Tang, Adv. Mater., 2014, 26, 5429.

57 N. L. Selivanov, L. G. Samsonova, V. Y. Artyukhov and T. N. Kopylova, Russ. Phys. J., 2011, 54, 601.

58 G. Dördelmann, H. Pfeiffer, A. Birkner and U. Schatzschneider, Inorg. Chem., 2011, 50, 4362. 